ARTICLE

Check for updates

https://doi.org/10.1038/s41467-021-26541-z

\title{
Self-wetting triphase photocatalysis for effective and selective removal of hydrophilic volatile organic compounds in air
}

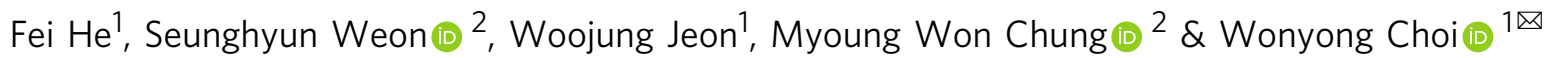

Photocatalytic air purification is widely regarded as a promising technology, but it calls for more efficient photocatalytic materials and systems. Here we report a strategy to introduce an in-situ water (self-wetting) layer on $\mathrm{WO}_{3}$ by coating hygroscopic periodic acid (PA) to dramatically enhance the photocatalytic removal of hydrophilic volatile organic compounds (VOCs) in air. In ambient air, water vapor is condensed on $\mathrm{WO}_{3}$ to make a unique tri-phasic (air/water $/ \mathrm{WO}_{3}$ ) system. The in-situ formed water layer selectively concentrates hydrophilic VOCs. PA plays the multiple roles as a water-layer inducer, a surface-complexing ligand enhancing visible light absorption, and a strong electron acceptor. Under visible light, the photogenerated electrons are rapidly scavenged by periodate to produce more $\bullet \mathrm{OH}$. PA/ $\mathrm{WO}_{3}$ exhibits excellent photocatalytic activity for acetaldehyde degradation with an apparent quantum efficiency of $64.3 \%$ at $460 \mathrm{~nm}$, which is the highest value ever reported. Other hydrophilic VOCs like formaldehyde that are readily dissolved into the in-situ water layer on $\mathrm{WO}_{3}$ are also rapidly degraded, whereas hydrophobic VOCs remain intact during photocatalysis due to the "water barrier effect". $\mathrm{PA} / \mathrm{WO}_{3}$ successfully demonstrated an excellent capacity for degrading hydrophilic VOCs selectively in wide-range concentrations (0.5-700 ppmv).

\footnotetext{
${ }^{1}$ Division of Environmental Science and Engineering, Pohang University of Science and Technology (POSTECH), Pohang 37673, Korea. ${ }^{2}$ School of Health and Environmental Science, Korea University, Seoul 02841, Korea. ${ }^{\bowtie}$ email: wchoi@postech.edu
} 
$\mathrm{V}$ olatile organic compounds (VOCs) are major components of air pollution, which significantly deteriorate air quality and seriously affect human health ${ }^{1-3}$. A common control method for VOCs is adsorption using porous medium (e.g., activated carbon, zeolite, MOFs, etc.) ${ }^{4,5}$, but their equilibrium adsorption capacity decreases significantly with lowering VOCs concentration ${ }^{6}$. Photocatalysis is widely considered as a promising method for air purification because of its ability to operate under ambient temperature and pressure conditions and to degrade and mineralize $\mathrm{VOCs}^{7-9}$. Photocatalytic degradation (PCD) maintains its removal efficiency even in the low concentration range ${ }^{3,10}$, which is more advantageous to deal with VOCs in sub-ppm levels (e.g., indoor air) ${ }^{11}$. Considering that visible light takes a much higher proportion ( 43\%) of solar light than UV light ( $4 \%)$ and a dominant portion of indoor light, it is essential to develop visible-light-responsive photocatalysts for practical application of air purification ${ }^{12}$. However, the performance of visible-light-driven photocatalysts is generally much lower than UV photocatalysis and needs significant improvements to satisfy the requirements for practical air purification ${ }^{13}$. As the PCD of VOCs is initiated mainly by hydroxyl radical $(\bullet \mathrm{OH})$ attack $^{14-16}$, an efficient way of enhancing visible light $\mathrm{PCD}$ is to facilitate the generation of $\bullet \mathrm{OH}$.

$\mathrm{WO}_{3}$ is one of the most frequently investigated photocatalysts with notable visible light activity $\left(E_{\mathrm{g}} \approx 2.8 \mathrm{eV}\right)^{10,17,18}$, which is also stable in oxidative and acidic condition ${ }^{19}$. Although its valence band (VB) edge potential (at about $3.0 \mathrm{~V}_{\mathrm{NHE}}$ ) is positive enough to generate $\mathrm{OH}$ radicals $\left(\cdot \mathrm{OH} / \mathrm{H}_{2} \mathrm{O}, E^{0}=+2.8 \mathrm{~V}_{\mathrm{NHE}}\right)^{13}$, its conduction band $(\mathrm{CB})$ edge potential $\left(\sim 0.4 \mathrm{~V}_{\mathrm{NHE}}\right)^{10}$ is not negative enough to make $\mathrm{CB}$ electrons scavenged by $\mathrm{O}_{2}$ via a single-electron transfer (e.g., $\left.\mathrm{O}_{2} / \mathrm{O}_{2} \bullet^{\bullet}, E^{0}=-0.33 \mathrm{~V}_{\mathrm{NHE}} ; \mathrm{O}_{2} / \mathrm{HO}_{2} \bullet, E^{0}=-0.05 \mathrm{~V}_{\mathrm{NHE}}\right)^{13,20}$. As a result, the photocatalytic activity of $\mathrm{WO}_{3}$ is highly limited due to the rapid charge recombination ${ }^{21,22}$. Many attempts have been made to increase the visible light activity of $\mathrm{WO}_{3}$ and one of the most effective methods is to load Pt nanoparticles as a co-catalyst ${ }^{23}$, which enables the multi-electron reduction of $\mathrm{O}_{2}$ to $\mathrm{H}_{2} \mathrm{O}_{2}$ or $\mathrm{H}_{2} \mathrm{O}$ at the $\mathrm{WO}_{3} \mathrm{CB}$ edge potential $\left(\mathrm{O}_{2} / \mathrm{H}_{2} \mathrm{O}_{2}, E^{0}=+0.68 \mathrm{~V}_{\mathrm{NHE}} ; \mathrm{O}_{2} /\right.$ $\left.\mathrm{H}_{2} \mathrm{O}, E^{0}=+1.23 \mathrm{~V}_{\mathrm{NHE}}\right)^{24-26}$ with facilitating the charge separation and subsequently $\mathrm{OH}$ radical production ${ }^{27}$. However, the use of expensive Pt cocatalyst limits its practical application ${ }^{28}$, which calls for a more economical method utilizing cheaper material. In typical PCD mechanisms working on the gas-solid interface, photogenerated holes most likely react with adsorbed water molecules (or surface hydroxyl groups) to form $\bullet \mathrm{OH}^{11,29}$. Water molecules are not only a source of $\bullet \mathrm{OH}$ but also an adsorbent competing with VOCs for the surface sites ${ }^{30,31}$; the dual effects of water vapor affect the PCD of VOCs differently depending on the hydrophilic and hydrophobic nature of $\mathrm{VOCs}^{32}$.

In this work, we propose to utilize water in a uniquely different way for the removal of VOCs by introducing an in situ water layer on the photocatalyst surface in ambient air. The presence of a thin surface water layer selectively solubilizes and concentrates hydrophilic VOCs in it, which subsequently facilitates their PCD. To achieve this, periodic acid (PA, $\mathrm{HIO}_{4} \cdot 2 \mathrm{H}_{2} \mathrm{O}$ ) as a highly hygroscopic substance was employed to induce an in situ water layer formed between the photocatalyst surface and air phase; as a result, the gas-solid interface can be transformed into a gas-liquid-solid (triphase) interface. In addition, the highly oxidizing $\mathrm{PA}^{33,34}$ has the potential to serve as a strong scavenger of $\mathrm{CB}$ electrons, which should enhance the formation of $\bullet \mathrm{OH}$ via the hole transfer. Herein, the $\mathrm{PA} / \mathrm{WO}_{3}$ system was employed for the PCD of several VOCs to propose a concept of PA-assisted photocatalysis that employs the in situ formation of the water layer on the photocatalyst surface. The low-cost PA-loaded $\mathrm{WO}_{3}$ exhibits even higher activity than Pt-loaded $\mathrm{WO}_{3}$ for the PCDs of hydrophilic VOCs.
This presents a cost-effective technology for high-performance selective degradation of hydrophilic VOCs.

\section{Results}

Enhanced activities of PA-coated photocatalysts. PA was combined with three common visible-light photocatalysts $\left(\mathrm{BiVO}_{4}\right.$, $\mathrm{N}-\mathrm{TiO}_{2}$, and $\mathrm{WO}_{3}$ ), and their photocatalytic activities were tested for acetaldehyde (AA) degradation in a closed-circulation reactor (Supplementary Fig. 1) under visible light $(\lambda>420 \mathrm{~nm})$. Each PCD test consisted of a dark circulation period $(20 \mathrm{~min})$ for adsorption equilibrium and the following irradiation period. Figure 1a shows the degradation of $\mathrm{AA}$ and the accompanying production of $\mathrm{CO}_{2}$ over bare and PA-treated $\mathrm{WO}_{3}, \mathrm{~N}-\mathrm{TiO}_{2}$, and $\mathrm{BiVO}_{4}$. The $\mathrm{PCD}$ rate constant $\left(k_{\mathrm{d}}\right)$, removal efficiency, and mineralization efficiency are summarized in Supplementary Table 1 . The photocatalytic activities of $\mathrm{WO}_{3}, \mathrm{~N}-\mathrm{TiO}_{2}$, and $\mathrm{BiVO}_{4}$ were significantly improved by the PA treatment among which $\mathrm{PA} / \mathrm{WO}_{3}$ exhibited the highest $\mathrm{PCD}$ activity. PA also has a similar PCD-promoting effect for $\mathrm{TiO}_{2}$ (P25) under UV irradiation (Supplementary Fig. 2), which confirms that the PA effect is the same regardless of the kind of photocatalysts. Interestingly, the photocatalytic activities of $\mathrm{PA} / \mathrm{P} 25$ and $\mathrm{PA} / \mathrm{WO}_{3}$ are similar under LED irradiation of $365 \mathrm{~nm}$ while $\mathrm{PA} / \mathrm{WO}_{3}$ is far more active than PA/P25 under $460 \mathrm{~nm}$ LED irradiation (see Supplementary Figs. 2 and 3). It is particularly notable that PA/ $\mathrm{WO}_{3}$ exhibited higher activity than $\mathrm{Pt} / \mathrm{WO}_{3}$ which is one of the most active visible-light photocatalysts ${ }^{10,23,27}$. The optimal composition of $\mathrm{PA} / \mathrm{WO}_{3}$ was tested by varying the mixing ratio of $\mathrm{PA}: \mathrm{WO}_{3}$ which exhibits good activity for a wide range of $\mathrm{PA}: \mathrm{WO}_{3}$ mass ratios between 2/3 and 3/2 (see Supplementary Fig. 4). The highest PCD activity was observed at the 1:1 mass ratio of $\mathrm{PA}: \mathrm{WO}_{3}$, which was used in the preparation of $\mathrm{PA} / \mathrm{WO}_{3}$. As shown in Fig. $1 \mathrm{~b}$ and c, the AA degradation and the concurrent $\mathrm{CO}_{2}$ production over $\mathrm{PA} / \mathrm{WO}_{3}$ were about 2.7 times and 4.0 times higher than that of $\mathrm{Pt} / \mathrm{WO}_{3}$, respectively. It should be also noted that $\mathrm{PA} / \mathrm{WO}_{3}$ exhibited similar enhanced PCD activities under different irradiation conditions of blue LED $(\lambda=460 \mathrm{~nm})$, UV LED $(\lambda=365 \mathrm{~nm})$ and halogen lamp $(\lambda>420 \mathrm{~nm}$ ) (Supplementary Fig. 3, Supplementary Table 2). The $\mathrm{AQE}$ of $\mathrm{PA} / \mathrm{WO}_{3}$ in the PCD of AA reached $16.1 \%$ and $22.3 \%$ under blue LED $(\lambda=460 \mathrm{~nm})$ and UV LED $(\lambda=365 \mathrm{~nm})$ irradiation, respectively, which were much higher than that of bare $\mathrm{WO}_{3}$ (Supplementary Fig. 5). PA/ $\mathrm{WO}_{3}$ rapidly degraded AA of different initial concentrations $\left([\mathrm{AA}]_{0}=120-700 \mathrm{ppmv}\right)$ under blue LED irradiation (Supplementary Fig. 6). As $[\mathrm{AA}]_{0}$ increased, $\mathrm{AQE}$ continued to increase until $[\mathrm{AA}]_{0}$ reached $600 \mathrm{ppmv}$. This indicates that more AA molecules are concentrated in the surface region with increasing the gas-phase AA concentration, implying the unique $\mathrm{AA}$-accumulating behavior of $\mathrm{PA} / \mathrm{WO}_{3}$. An $\mathrm{AQE}$ as high as $64.3 \%$ was achieved when $[\mathrm{AA}]_{0}$ was $700 \mathrm{ppmv}$. As far as we know, this $A Q E$ value is significantly higher than any other reported ones for the visible-light-driven PCD of AA (Supplementary Table 3). In addition, the $\mathrm{AQE}$ of $\mathrm{PA} / \mathrm{WO}_{3}$ is also remarkable to our knowledge among the reported $\mathrm{WO}_{3}$-based visible-light PCD systems (Supplementary Table 4). To check the long-term durability of the PA component, the $\mathrm{PA} / \mathrm{WO}_{3}$ sample that had been stored for 6 months under ambient conditions was tested for its PCD activity, which was little different from that of the fresh $\mathrm{PA} / \mathrm{WO}_{3}$. This demonstrates that the $\mathrm{PA} / \mathrm{WO}_{3}$ sample can be kept in long-term storage without losing its catalytic activity (see Supplementary Fig. 7). The above results showed the excellent performance of PA/ $\mathrm{WO}_{3}$ as a visible-light photocatalyst for the degradation of AA that is a common indoor air pollutant.

To clarify the synergistic effect between $\mathrm{PA}$ and $\mathrm{WO}_{3}$, other iodine-containing inorganic compounds including $\mathrm{NaIO}_{4}, \mathrm{NaIO}_{3}$, $\mathrm{NaI}$, and $\mathrm{HIO}_{3}$ were also tested for their effects on the PCD activity of $\mathrm{WO}_{3}$. Their activity decreased in the following order: 

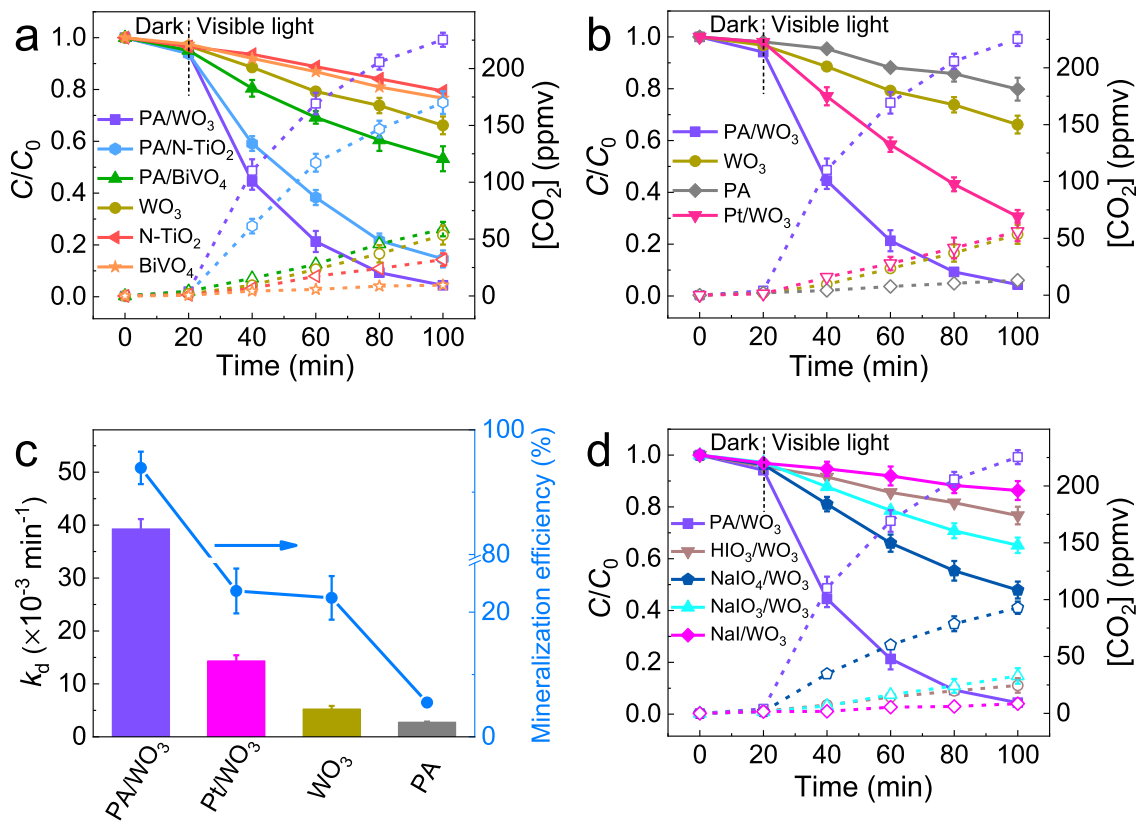

Fig. 1 Visible light-driven PCD of acetaldehyde (AA). a The time profiles of the PCD of $A A$ and the accompanying production of $C_{2}$ on bare and $P A-$ treated $\mathrm{WO}_{3}, \mathrm{~N}-\mathrm{TiO}_{2}$, and $\mathrm{BiVO}_{4}$. b The PCD comparison between $\mathrm{PA} / \mathrm{WO}_{3}$ and $\mathrm{Pt} / \mathrm{WO}_{3}$. $\mathbf{c}$ The $\mathrm{PCD}$ rate constant $\left(k_{\mathrm{d}}\right)$ and the mineralization efficiency after 80 min reaction for $\mathrm{PA} / \mathrm{WO}_{3}, \mathrm{Pt} / \mathrm{WO}_{3}$, bare $\mathrm{PA}$, and $\mathrm{WO}_{3}$. d $\mathrm{PCD}$ activities of $\mathrm{WO}_{3}$ treated with different iodine reagents. The dashed lines with open symbols represent the $\mathrm{CO}_{2}$ concentration generated from AA degradation. Error bars are defined as standard deviation. Experimental conditions: $[A A]_{0}=120$ ppmv; visible light $(\lambda>420 \mathrm{~nm})$ intensity of $2.2 \mathrm{~mW} / \mathrm{cm}^{2}$; sample amount of $50 \mathrm{mg}$; $\mathrm{RH} 65 \%$; reaction temperature of $30{ }^{\circ} \mathrm{C}$.

$\mathrm{PA} / \mathrm{WO}_{3} » \mathrm{NaIO}_{4} / \mathrm{WO}_{3}>\mathrm{NaIO}_{3} / \mathrm{WO}_{3} \approx \mathrm{WO}_{3}>\mathrm{HIO}_{3} / \mathrm{WO}_{3}>\mathrm{NaI} /$ $\mathrm{WO}_{3}$ (Fig. 1d and Supplementary Table 1). Only periodate compounds showed obvious enhancement effects on the PCD activity of $\mathrm{WO}_{3}$. In general, periodate-based compounds with high-valence-state iodine exhibit stronger electron-accepting and oxidizing capacity. The standard 2-electron reduction potential of $\mathrm{IO}_{4}^{-}$was much higher than that of $\mathrm{IO}_{3}^{-}\left[E^{0}\left(\mathrm{IO}_{4}^{-}-\right.\right.$ $\left.\left.\mathrm{IO}_{3}{ }^{-}\right)=+1.623 \mathrm{~V}_{\mathrm{NHE}}\right)^{35,36}$ and $\left(E^{0}\left(\mathrm{IO}_{3}{ }^{-} / \mathrm{HIO}_{2}\right) \approx+0.88 \mathrm{~V}_{\mathrm{NHE}}\right]^{37}$. Therefore, periodate ions should be responsible for the efficient trapping of $\mathrm{CB}$ electrons in the combined $\mathrm{WO}_{3}-\mathrm{IO}_{4}{ }^{-}$system. However, it is interesting to note that the PCD activity of $\mathrm{NaIO}_{4} /$ $\mathrm{WO}_{3}\left(k_{\mathrm{d}}=9.65 \times 10^{-3} \mathrm{~min}^{-1}\right)$ was much lower than that of PA/ $\mathrm{WO}_{3}\left(k_{\mathrm{d}}=39.3 \times 10^{-3} \mathrm{~min}^{-1}\right)$. We observed that the surface of the $\mathrm{PA} / \mathrm{WO}_{3}$ catalyst became wet spontaneously after its exposure to ambient air while this phenomenon did not occur at all in the case of $\mathrm{NaIO}_{4} / \mathrm{WO}_{3}$. A similar effect of PA was also found on $\mathrm{N}-\mathrm{TiO}_{2}$ (Supplementary Fig. 8). Based on this observation, we hypothesized that this spontaneously formed surface layer may influence the photocatalytic activity of $\mathrm{PA} / \mathrm{WO}_{3}$ during the $\mathrm{PCD}$ of $\mathrm{AA}$ and further investigated the effect of water on the PCD activity.

The above PCD experiments employed high concentrations of AA ranging in 120-700 ppmv, which is unrealistically high for indoor environments. To demonstrate the performance of the $\mathrm{PA} / \mathrm{WO}_{3}$ photocatalyst in a more realistic condition, the $\mathrm{PCD}$ of formaldehyde (FA) on $\mathrm{PA} / \mathrm{WO}_{3}$ was additionally tested at a much lower concentration of $500 \mathrm{ppbv}$ in a larger reactor $(1.5 \mathrm{~L})$ (compared with the PCD condition of AA) (see Fig. 2). FA is a common indoor air pollutant and a human carcinogen classified by the World Health Organization (WHO). The FA PCD tests were conducted under blue LED $(\lambda=460 \mathrm{~nm})$ irradiation. After 30 min PCD reaction, the concentration of FA decreased from 500 to $58 \mathrm{ppbv}$ (lower than the limit concentration allowed by WHO, $80 \mathrm{ppbv}^{38}$ ) over $50 \mathrm{mg} \mathrm{PA} / \mathrm{WO}_{3}$. Note that FA could be removed by $\mathrm{PCD}$ using as low as $1 \mathrm{mg} \mathrm{PA} / \mathrm{WO}_{3}$. The activity of $\mathrm{PA} / \mathrm{WO}_{3}$ was far higher than bare $\mathrm{WO}_{3}$ (Fig. 2b), and it remained active even after 10 PCD cycles (Fig. 2c). The above results confirm that $\mathrm{PA} / \mathrm{WO}_{3}$ has an excellent capacity for degrading hydrophilic VOCs (FA and AA) selectively in wide-range concentrations $(500 \mathrm{ppbv}-700 \mathrm{ppmv})$. No other existing indoor air purification methods have such effective, durable, and selective capacity for the removal of indoor aldehydes under ambient conditions.

Roles of PA and in situ formed water layer. PA molecules with hydroxyl groups are highly hygroscopic due to the hydrogen bonding between water molecules and the hydroxyl groups in $\mathrm{PA}^{39}$. On the other hand, $\mathrm{NaIO}_{4}$ is not hygroscopic due to the absence of hydroxyl groups. To evaluate the water absorption capacity, fresh air with $65 \% \mathrm{RH}$ was flowed over the surface of bare $\mathrm{WO}_{3}, \mathrm{NaIO}_{4} / \mathrm{WO}_{3}$, and $\mathrm{PA} / \mathrm{WO}_{3}$ samples for $30 \mathrm{~min}$; then, the weight increased in each catalyst sample was measured (Fig. 3a). The weight of bare $\mathrm{WO}_{3}$ and $\mathrm{NaIO}_{4} / \mathrm{WO}_{3}$ was not changed while that of $\mathrm{PA} / \mathrm{WO}_{3}$ increased by $\sim 26 \%$, which can be attributed to liquid water condensed on $\mathrm{PA} / \mathrm{WO}_{3}$ from the humid air. Although water molecules should be adsorbed on the bare $\mathrm{WO}_{3}$ surface via hydrogen bonding with the surface hydroxyl groups ${ }^{40}$, the adsorbed water molecules do not induce the condensation of the water layer on $\mathrm{WO}_{3}$. It seems that the presence of PA facilitates the condensation of the water layer on the surface of the catalyst. To further confirm the in situ formation of the water layer via condensation, the $\mathrm{PA} / \mathrm{WO}_{3}$ coated on the glass was exposed in ambient air for $10 \mathrm{~min}$, then the sample was in situ observed with microphotography (see the Supplementary video). We observed that the formation of condensing water layer induces the movement of $\mathrm{WO}_{3}$ particles. When the wet $\mathrm{PA} / \mathrm{WO}_{3}$ sample was dried by an external heater, PA crystals appeared with ceasing the moving of $\mathrm{WO}_{3}$ particles. Upon stopping the heating, the water absorption process resumed with redissolving PA crystals and moving $\mathrm{WO}_{3}$ particles again. The FT-IR spectral changes in $\mathrm{PA} / \mathrm{WO}_{3}$ and bare $\mathrm{WO}_{3}$ before and after the exposure to humid air also show such a trend clearly (Fig. 3b). The peak assigned to the stretching vibration of surface $\mathrm{OH}$ is located at 

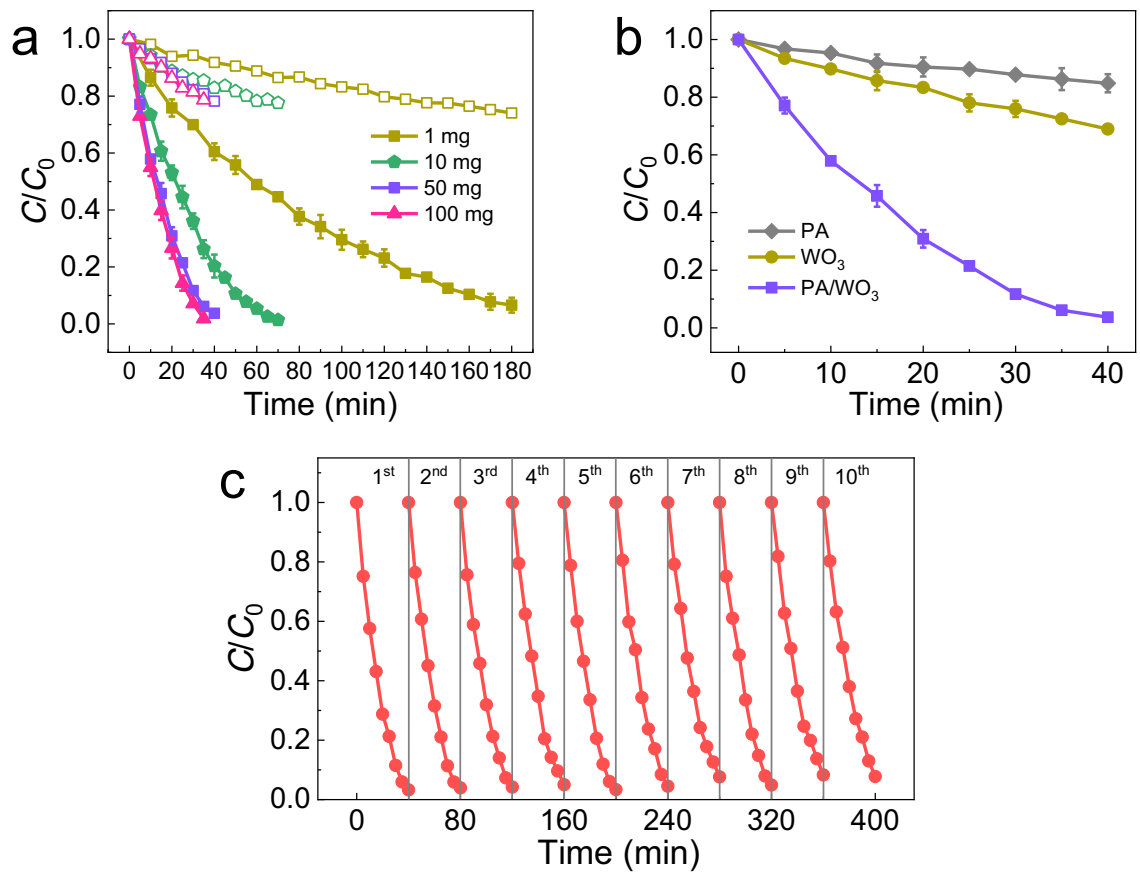

Fig. 2 Visible light-driven PCD of formaldehyde (FA) at $\mathbf{5 0 0} \mathbf{~ p p b v}$ on $\mathbf{P A} / \mathbf{W O}_{\mathbf{3}}$. a The dark control tests (open symbols) and the PCD tests (filled symbols) over $\mathrm{PA} \mathrm{WO}_{3}$ (1:1) with different catalyst mass (e.g., $10 \mathrm{mg}$ catalyst composed of $5 \mathrm{mg} \mathrm{PA}$ and $5 \mathrm{mg} \mathrm{WO}_{3}$ ). $\mathbf{b} \mathrm{PCD}$ of $\mathrm{FA}$ on $\mathrm{PA} / \mathrm{WO}_{3}$, bare $\mathrm{WO}_{3}$ and PA. Error bars are defined as standard deviation. c Repeated PCD cycles of FA degradation over 50 mg PA/ $\mathrm{WO}_{3}$. Experimental conditions: $[F A]_{0}=500 \mathrm{ppbv}$; blue LED $(\lambda=460 \mathrm{~nm})$ intensity of $2.0 \mathrm{~mW} / \mathrm{cm}^{2} ; \mathrm{RH} 65 \%$; reaction temperature of $30^{\circ} \mathrm{C}$.
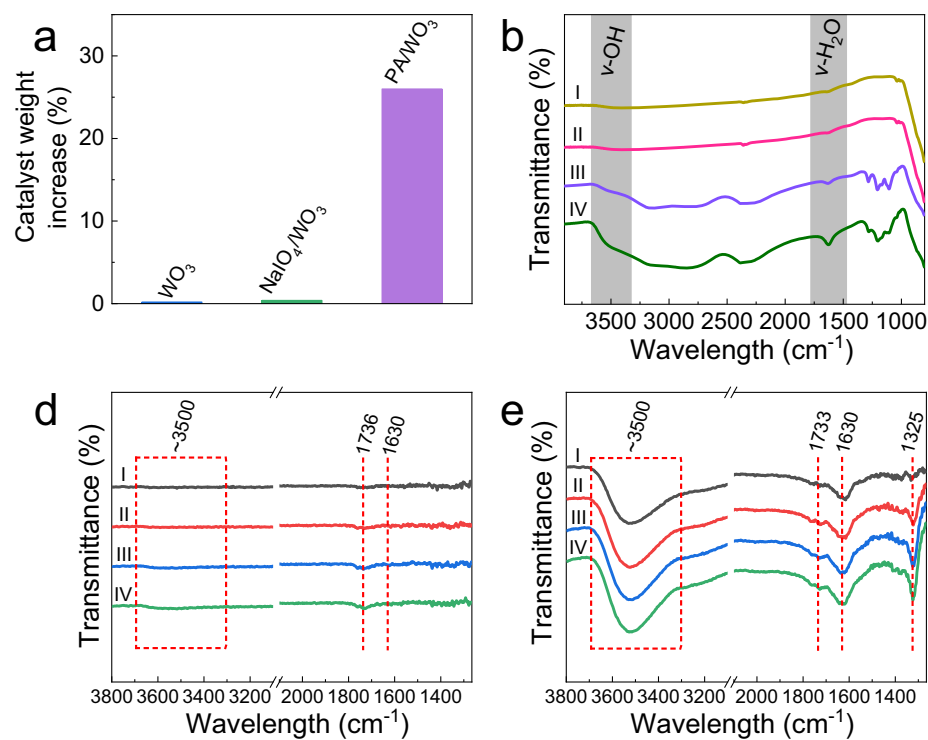
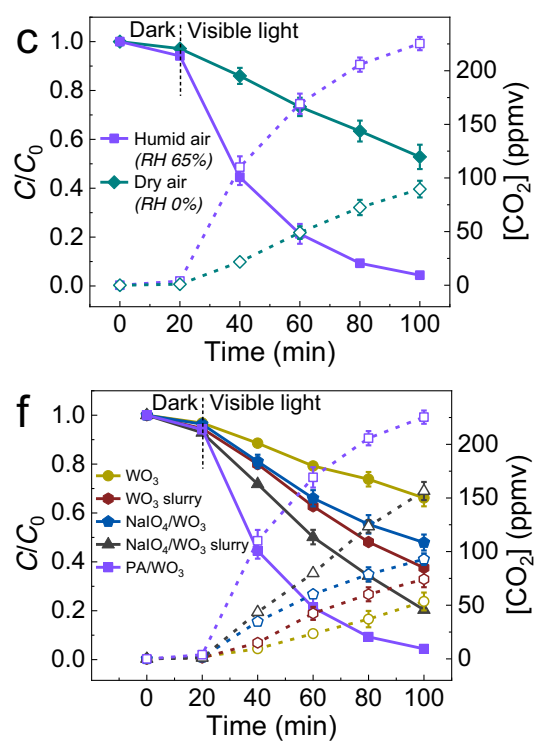

Fig. 3 Formation and effects of the in situ formed water layer. a Catalyst weight increase of $\mathrm{PA} / \mathrm{WO}_{3}, \mathrm{NalO}_{4} / \mathrm{WO}_{3}$, and bare $\mathrm{WO}$ samples after exposing each catalyst under humid air $(\mathrm{RH} 65 \%)$ for $30 \mathrm{~min}$. $\mathrm{RH}$ is defined as relative humidity. b FT-IR spectra of bare $\mathrm{WO}_{3}(\mathrm{I})$ before and (II) after exposure to humid air, and those of $\mathrm{PA} / \mathrm{WO}_{3}$ (III) before and (IV) after exposure to humid air for 30 min. $\mathbf{c} \mathrm{PCD}$ activity of PA/WO $\mathrm{W}_{3}$ for acetaldehyde (AA) degradation after exposure to dry and humid air for $30 \mathrm{~min}$. In situ DRIFT spectra for $\mathbf{d} \mathrm{PA} / \mathrm{WO}_{3}$ after exposing the sample to $300 \mathrm{ppmv} \mathrm{AA} / \mathrm{dry}$ air stream and e PA/ $/ \mathrm{WO}_{3}$ in 300 ppmv AA/RH 65\% air stream for (I) $10 \mathrm{~s}$, (II) $1 \mathrm{~min}$, (III) $3 \mathrm{~min}$, and (IV) 5 min. The spectra of the dry PA/WO 3 surface were collected and used as the background. $\mathbf{f} \mathrm{PCD}$ activity of bare $\mathrm{WO}_{3}, \mathrm{NalO}_{4} / \mathrm{WO}_{3}$, and their slurries containing 26 wt\% water for the degradation of AA. The dashed lines with open symbols represent the $\mathrm{CO}_{2}$ concentration generated from AA degradation. Error bars are defined as standard deviation. Experimental conditions: $[A A]_{0}=120$ ppmv; visible light $\left(\lambda>420 \mathrm{~nm}\right.$ ) intensity of $2.2 \mathrm{~mW} / \mathrm{cm}^{2}$; sample amount of $50 \mathrm{mg}$ (with $13 \mathrm{mg}$ of extra water in the case of $\mathrm{WO}_{3}$ slurry and $\mathrm{NaIO}_{4} / \mathrm{WO}_{3}$ slurry); reaction temperature of $30^{\circ} \mathrm{C}$. 
$3600-3200 \mathrm{~cm}^{-1}(v-\mathrm{OH})$, while the signal of bending vibration of adsorbed water appeared at $\sim 1630 \mathrm{~cm}^{-1}\left(v-\mathrm{H}_{2} \mathrm{O}\right)^{41}$. The signals of both $(v-\mathrm{OH})$ and $\left(v-\mathrm{H}_{2} \mathrm{O}\right)$ for bare $\mathrm{WO}_{3}$ remained almost unchanged after exposure to humid air, which confirms that bare $\mathrm{WO}_{3}$ surface does not induce significant water adsorption. However, these signals on $\mathrm{PA} / \mathrm{WO}_{3}$ were markedly enhanced after exposure to humid air, which indicates the condensation of water. The strong hydrogen bonding between the hydroxyl groups of PA and water molecules should make the condensation of water vapor highly exothermic at ambient conditions, where the negative $\Delta H$ outweighs the entropy decrease of water vapor condensation to make the overall condensation process thermodynamically spontaneous $(\Delta G<0)$. Therefore, the interfacial characteristics in the catalyst surface region of $\mathrm{PA} / \mathrm{WO}_{3}$ should be changed from the two-phase gas-solid interaction to the threephase gas-liquid-solid interaction after the PA-induced condensation of the water layer.

To clarify the effect of water, the PCD activities of $\mathrm{PA} / \mathrm{WO}_{3}$ were compared between the dry $(0 \% \mathrm{RH})$ and humid air $(65 \%$ $\mathrm{RH}$ ) conditions (Fig. 3c). Both the degradation of $\mathrm{AA}$ and the accompanying production of $\mathrm{CO}_{2}$ over $\mathrm{PA} / \mathrm{WO}_{3}$ were significantly reduced under the dry air condition, which confirms that the role of water vapor is critical in controlling the overall PCD process. However, if not in the dry condition, the humidity variation ranging in $\mathrm{RH} 40-90 \%$ has a minor influence on the $\mathrm{PCD}$ of $\mathrm{AA}$ on $\mathrm{PA} / \mathrm{WO}_{3}$ (see Supplementary Fig. 9). It should be also noted that $\mathrm{PA} / \mathrm{WO}_{3}$ showed higher $\mathrm{PCD}$ activity than bare $\mathrm{WO}_{3}$ even in dry air (Figs. 1a vs. 3c). The adsorption of VOCs is the first step in gas-solid photocatalytic reaction, and the adsorption properties of VOCs often significantly affect the PCD efficiency ${ }^{42}$. In the case of $\mathrm{PA} / \mathrm{WO}_{3}$ in humid air condition, the spontaneous formation of the liquid water layer on the catalyst surface should hinder the direct contact between VOC molecules and the $\mathrm{WO}_{3}$ surface, which makes the reaction medium involve all three phases. As a result, the first step in PCD should be changed from the adsorption of $\mathrm{AA}$ on the $\mathrm{WO}_{3}$ surface to the dissolution of AA in the surface water layer. Hydrophilic AA is highly soluble in water at room temperature ${ }^{43}$. The dark adsorptive removal of $\mathrm{AA}$ over $\mathrm{PA} / \mathrm{WO}_{3}$ was compared after 30 min equilibration under dry air and humid air $(65 \% \mathrm{RH})$. It is found that $6.5 \%$ and $18.6 \%$ of $\mathrm{AA}$ is adsorbed on the catalyst surface within $100 \mathrm{~min}$ under dry and humid air conditions, respectively, which indicates that the existence of a water layer promoted the uptake of AA on the catalyst surface.

The relation between $\mathrm{AA}$ and the surface water layer was further investigated by in situ DRIFT spectroscopy under dark conditions. When exposing $\mathrm{PA} / \mathrm{WO}_{3}$ to $300 \mathrm{ppmv} \mathrm{AA} /$ dry airflow (see Fig. 3d), no peaks corresponding to $v$-OH $\left(3600-3200 \mathrm{~cm}^{-1}\right.$ ) and $v-\mathrm{H}_{2} \mathrm{O}\left(\sim 1630 \mathrm{~cm}^{-1}\right)$ were found, which indicates that the formation of the surface water layer is negligible. The small peak located at $1736 \mathrm{~cm}^{-1}(v-\mathrm{C}=\mathrm{O}$ vibration mode in aldehydes) is assigned to AA adsorbed via hydrogen bonding with a surface $\mathrm{OH}$ group ${ }^{44}$. On the other hand, the $v-\mathrm{OH}\left(3600-3200 \mathrm{~cm}^{-1}\right), v-\mathrm{H}_{2} \mathrm{O}$ $\left(\sim 1630 \mathrm{~cm}^{-1}\right)$, and $v$-C $=\mathrm{O}\left(1733 \mathrm{~cm}^{-1}\right)$ peaks all increased significantly when exposing $\mathrm{PA} / \mathrm{WO}_{3}$ to 300 ppmv $\mathrm{AA} / 65 \% \mathrm{RH}$ airflow, which indicates the formation of the surface water layer and the enrichment of AA (see Fig. 3e). Moreover, a distinct peak corresponding to $\mathrm{C}-\mathrm{O}$ stretching vibration $(v-\mathrm{C}-\mathrm{O})$ for carboxylic acids $\left(1325 \mathrm{~cm}^{-1}\right)^{45,46}$ gradually appeared with time. This implies that the in situ water layer formation facilitates not only adsorption/dissolution of AA but also partial pre-oxidation of AA, which subsequently accelerates the PCD process under irradiation.

To further confirm the role of the surface water layer, an aliquot of water was added to $\mathrm{WO}_{3}$ powder to make a slurry (with and without $\mathrm{NaIO}_{4}$ ): $13 \mathrm{mg}$ water was well mixed with $50 \mathrm{mg} \mathrm{WO}_{3}$ or
$50 \mathrm{mg} \mathrm{NaIO} / \mathrm{WO}_{3}$ (w/w: $1 / 1$ ) to form slurries. The resulting slurry photocatalysts and the corresponding dry photocatalysts were compared for the PCD of AA (see Fig. 3f). The slurry photocatalysts (with and without $\mathrm{NaIO}_{4}$ ) showed higher $\mathrm{PCD}$ activity than the corresponding dry samples and the $\mathrm{NaIO}_{4} / \mathrm{WO}_{3}$ slurry exhibited higher PCD activity than pure $\mathrm{WO}_{3}$ in either slurry or dry state. This confirms that the high activity of $\mathrm{PA} / \mathrm{WO}_{3}$ should be ascribed to the combined action of $\mathrm{IO}_{4}{ }^{-}$and water. The PA acidity in PA/ $\mathrm{WO}_{3}$ may play a role as well since the $\mathrm{pH}$ of the $\mathrm{PA}$ solution was 1.5 whereas that of $\mathrm{NaIO}_{4}$ solution was 4.6. To test the acidity effect, the $\mathrm{pH}$ of $\mathrm{NaIO}_{4}$ solution was adjusted to 1.5 with adding iodic acid when preparing $\mathrm{NaIO}_{4} / \mathrm{WO}_{3}$ and the PCD activity of the acidified $\mathrm{NaIO}_{4} / \mathrm{WO}_{3}$ slurry was much higher than that of $\mathrm{NaIO}_{4} / \mathrm{WO}_{3}$ slurry (see Supplementary Fig. 10). Considering that iodic acid alone did not promote the PCD activity of $\mathrm{WO}_{3}$, the above result implies that the PA acidity in the water layer should contribute to the high PCD activity of $\mathrm{PA} / \mathrm{WO}_{3}$. This might be related to the fact that the reduction of periodate is favored at an acidic condition $\left(\mathrm{IO}_{4}^{-}+2 \mathrm{H}^{+}+2 \mathrm{e}^{-} \rightarrow \mathrm{IO}_{3}^{-}+\mathrm{H}_{2} \mathrm{O}\right)$. Therefore, the water-rich surface over $\mathrm{PA} / \mathrm{WO}_{3}$ should scavenge photogenerated holes more efficiently to produce $\bullet \mathrm{OH}$ and $\mathrm{AA}$ molecules that are dissolved and concentrated within the thin water layer should undergo the subsequent PCD reactions in the solid-water interface. This process should be much faster than that in the traditional gas-solid interfacial PCD reaction since the AA molecules in the surface water layer is far more concentrated and oxidized than those in the gas phase. The synergy between $\mathrm{IO}_{4}^{-}$and the water layer is further discussed in the following section.

The structural and surface properties of PA-treated $\mathrm{WO}_{3}$ were evaluated by using XRD, FE-SEM, $\mathrm{N}_{2}$ adsorption-desorption, XPS, DRS techniques, and density functional theory (DFT) calculations. As shown in Fig. 4a, the position of diffraction peaks in the XRD pattern of $\mathrm{PA} / \mathrm{WO}_{3}$ was consistent with those of monoclinic $\mathrm{WO}_{3}$ (JCPDS-ICDD card \#75-2072) and $\mathrm{HIO}_{4} \cdot 2 \mathrm{H}_{2} \mathrm{O}$ (JCPDS-ICDD card \#74-0334). No characteristic peaks of any other phases were observed, indicating that the original crystal form of $\mathrm{WO}_{3}$ and $\mathrm{PA}$ was not affected in the prepared $\mathrm{PA} / \mathrm{WO}_{3}$ sample. In addition, PA treatment had a negligible effect on the BET surface area $\left(S_{\mathrm{BET}}\right)$, pore structure, and morphology of $\mathrm{WO}_{3}$ (see Supplementary Figs. 11 and 12). To evaluate the light absorption capacity of samples, the UV-vis spectra of $\mathrm{WO}_{3}$ and $\mathrm{PA} / \mathrm{WO}_{3}$ are compared in Fig. $4 \mathrm{~b}$. The light absorption capacity of $\mathrm{WO}_{3}$ was clearly enhanced in the range of 300-450 nm after combining with PA. This PA-enhanced absorption is more clearly seen in the difference DRS spectra (see the inset of Fig. $4 \mathrm{~b}$ ). The extra light absorption should not be ascribed to the formation of an in situ water layer on $\mathrm{PA} / \mathrm{WO}_{3}$ since the absorption spectrum of $\mathrm{WO}_{3}$ slurry ( $26 \mathrm{wt} \%$ water content) was a little different from that of dry $\mathrm{WO}_{3}$ powder. Therefore, the enhanced absorption in the $300-450 \mathrm{~nm}$ region (inset of Fig. 4b) where PA itself is optically transparent, should be ascribed to the surface interaction between PA and $\mathrm{WO}_{3}$. The XPS analysis was also employed to investigate the interaction between $\mathrm{PA}$ and $\mathrm{WO}_{3}$. In the measured W $4 f$ XPS spectra (Fig. 4c), the bare $\mathrm{WO}_{3}$ sample shows two binding energy (BE) peaks at 35.5 and $37.7 \mathrm{eV}$, which are assigned to $4 f_{7 / 2}$ and $4 f_{5 / 2}$ of $\mathrm{W}^{6+}$, respectively ${ }^{47}$. The two peaks of PA/ $\mathrm{WO}_{3}$ were shifted by $\sim 0.2 \mathrm{eV}$ to higher $\mathrm{BE}$ in comparison to those of bare $\mathrm{WO}_{3}$. Several studies showed that the inorganic acid treatment of $\mathrm{TiO}_{2}$ shifts the metal $\mathrm{BE}$ higher because of the strong interaction between the acid anions and metal cations ${ }^{48-50}$. It can be reasonably inferred that the oxygen atom in the PA molecule could be directly complexed with $\mathrm{W}$ cation on the surface of $\mathrm{WO}_{3}$ in the form of "W-O-I- $(\mathrm{OH})_{n}$ ". In this complex, the electron density on the $\mathrm{W}$ cation should be further decreased by the strong electron-withdrawing character of the iodine cation $\left(\mathrm{I}^{7+}\right)$, leading to the slight increase in the BE of $\mathrm{W} 4 f$. The I $3 d$ XPS spectra 

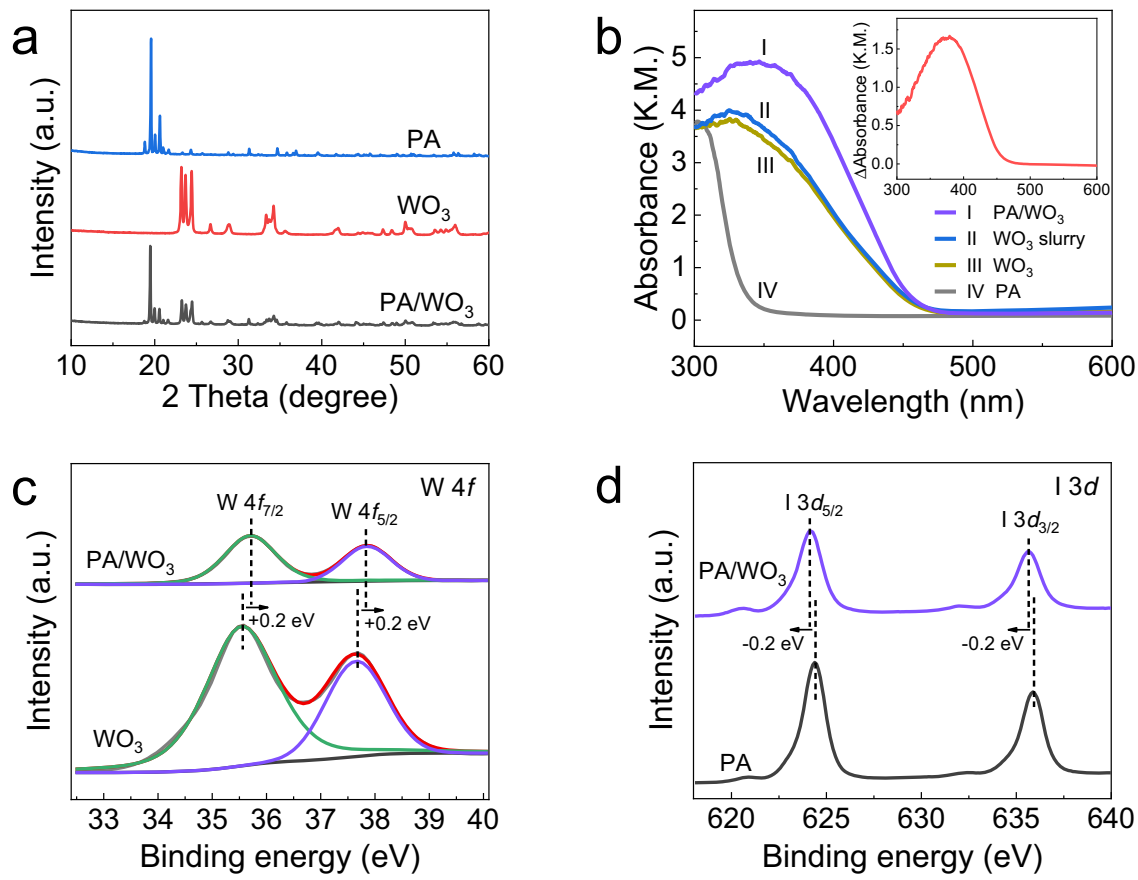

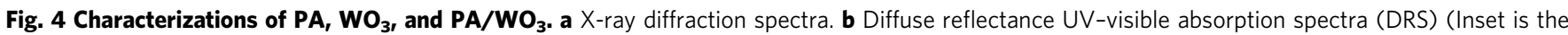
difference DRS spectrum which is obtained from the spectrum I minus the spectrum III). XPS spectra of $\mathbf{c}$ W $4 f$ and $\mathbf{d}$ I $3 d$ band.

(shown in Fig. 4d) may further support such a conclusion. The BEs of I $3 d_{5 / 2}$ and $\mathrm{I} 3 d_{3 / 2}$ for PA are at 624.4 and $635.9 \mathrm{eV}$, respectively, but those of $\mathrm{PA} / \mathrm{WO}_{3}$ exhibit a negative shift by $\sim 0.2 \mathrm{eV}$, which indicates the increased electron density on iodine. This suggests that the charge transfer in the "W-O-I- $(\mathrm{OH})_{n}$ " complex is induced by the "electron-withdrawing effect" of the iodine cation to decrease the electron density on $\mathrm{W}$ but to increase that on I. Such charge transfer complex formation on the $\mathrm{WO}_{3}$ surface not only facilitates the separation of photogenerated electron-hole pairs but also promotes the light absorption ability of $\mathrm{WO}_{3}{ }^{51-53}$, as supported by the enhanced light absorption of $\mathrm{PA} / \mathrm{WO}_{3}$ in Fig. 4b. Moreover, the DFT calculation that was carried out to investigate the interaction between $\mathrm{PA}$ and $\mathrm{WO}_{3}$ surface shows that the calculated adsorption/binding energy of $\mathrm{PA}$ on $\mathrm{WO}_{3}$ surface is $-3.7 \mathrm{eV}$, a high value which usually implies the formation of strong chemical bonds ${ }^{54}$. The charge density difference analysis shows that there is an electrondepleted region on the $\mathrm{WO}_{3}$ surface and an electron-gaining region around the iodine center. This clearly indicates that the charge is transferred from the $\mathrm{WO}_{3}$ surface to PA, which is consistent with the XPS results (see Supplementary Fig. 13).

The role of dioxygen was also investigated. The PCDs of AA over $\mathrm{PA} / \mathrm{WO}_{3}$ and bare $\mathrm{WO}_{3}$ were conducted under different $\mathrm{O}_{2}$ concentrations (Fig. 5a and b). In general, the PCD rate is faster with producing more $\mathrm{CO}_{2}$ at higher $\mathrm{O}_{2}$ concentration (as shown in Fig. 5b) since dioxygen serves as the main electron acceptor in gas-solid interface PCD reaction with the concurrent formation of reactive oxygen species (e.g., $\left.\mathrm{O}_{2} \bullet-, \mathrm{HO}_{2} \bullet\right)^{55}$. This effectively transfers electrons to facilitate the charge carrier separation, and the resulting reactive oxygen species play a key role in oxidizing VOCs. However, the PCD of AA over $\mathrm{PA} / \mathrm{WO}_{3}$ was a little dependent on $\mathrm{O}_{2}$ concentration and $120 \mathrm{ppmv}$ of AA could be completely removed even in the absence of $\mathrm{O}_{2}$ although the concurrent production of $\mathrm{CO}_{2}$ was a little reduced without $\mathrm{O}_{2}$ (Fig. 5a). This indicates that PA is a much stronger electron acceptor than dioxygen $\left[E^{0}\left(\mathrm{IO}_{4}^{-} / \mathrm{IO}_{3}^{-}\right)=+1.623 \mathrm{~V}_{\mathrm{NHE}}, E^{0}\right.$ $\left.\left(\mathrm{O}_{2} / \mathrm{O}_{2} \bullet^{-}\right)=-0.33 \mathrm{~V}_{\mathrm{NHE}}, E^{0}\left(\mathrm{O}_{2} / \mathrm{HO}_{2} \bullet\right)=-0.05 \mathrm{~V}_{\mathrm{NHE}}\right]^{13,35,36}$. The presence of $\mathrm{O}_{2}$ did not enhance the degradation rate of AA but moderately increased $\mathrm{CO}_{2}$ generation. This is consistent with the fact that $\mathrm{O}_{2}$ is needed as a reagent for the complete mineralization of aldehydes into $\mathrm{CO}_{2}{ }^{56}$.

The role of PA as the main electron acceptor implies that it should be consumed with irradiation time. Multi-cycle PCD experiments of AA over $\mathrm{PA} / \mathrm{WO}_{3}$ were conducted (Fig. 5c), which indeed exhibited a gradual decrease in the $\mathrm{PCD}$ rate. However, the PCD activity was maintained relatively high for a long irradiation period. In a comparison of the first and the fifth cycles, the removal of $\mathrm{AA}$ in $80 \mathrm{~min}$ decreased from $95.6 \%$ to $78.5 \%$, and the fraction of mineralized AA (estimated from the $\mathrm{CO}_{2}$ production) in 80 min was reduced from $93.9 \%$ to $70.3 \%$. Even after the fifth cycle, the PCD activity was far higher than bare $\mathrm{WO}_{3}$ (Fig. 1). FE-SEM, TEM, and XPS results showed that the morphology and surface chemical state of $\mathrm{WO}_{3}$ in $\mathrm{PA} /$ $\mathrm{WO}_{3}$ were little changed after the PCD reaction of AA (see Supplementary Figs. 12 and 14). The analysis of the iodinecontaining species in $\mathrm{PA} / \mathrm{WO}_{3}$ during the cyclic experiments (Fig. 5d) found that the $\mathrm{IO}_{4}{ }^{-}$portion decreased from $100 \%$ in the fresh $\mathrm{PA} / \mathrm{WO}_{3}$ to $90.5 \%$ after the first cycle, and further to $59.3 \%$ after the fifth cycle of AA degradation. At the same time, the $\mathrm{IO}_{3}{ }^{-}$portion increased from $0 \%$ to $9.5 \%$ after the first cycle, and further to $40.7 \%$ after the fifth cycle. On the other hand, no $\mathrm{I}^{-}$was detected throughout the multicycle experiments. It seems that the photocatalytic reaction of $\mathrm{IO}_{4}^{-}$with $\mathrm{CB}$ electrons leads to the production of $\mathrm{IO}_{3}{ }^{-}$as a main product on the visible light-irradiated $\mathrm{PA} / \mathrm{WO}_{3}$. The possible reoxidation of $\mathrm{IO}_{3}^{-}$to $\mathrm{IO}_{4}^{-}$can be ruled out since the control PCD tests of $\mathrm{AA}$ using $\mathrm{NaIO}_{3} / \mathrm{WO}_{3}$ and $\mathrm{HIO}_{3} / \mathrm{WO}_{3}$ showed no production of $\mathrm{IO}_{4}^{-}$. Therefore, the gradual decline of catalyst activity of $\mathrm{PA} / \mathrm{WO}_{3}$ in Fig. $5 \mathrm{c}$ should be ascribed to the consumption of $\mathrm{IO}_{4}{ }^{-}$. To regenerate the photocatalyst, the used $\mathrm{PA} / \mathrm{WO}_{3}$ was washed with water and reloaded with $0.11 \mathrm{~mol} / \mathrm{L}$ PA solution by following the same procedure as in the preparation of the fresh $\mathrm{PA} / \mathrm{WO}_{3}$. The regenerated $\mathrm{PA} / \mathrm{WO}_{3}$ catalyst almost fully recovered its original activity (see Fig. 5c, $\mathrm{VI}$ ), which confirms the critical role of PA as an electron acceptor in the PCD of AA. 

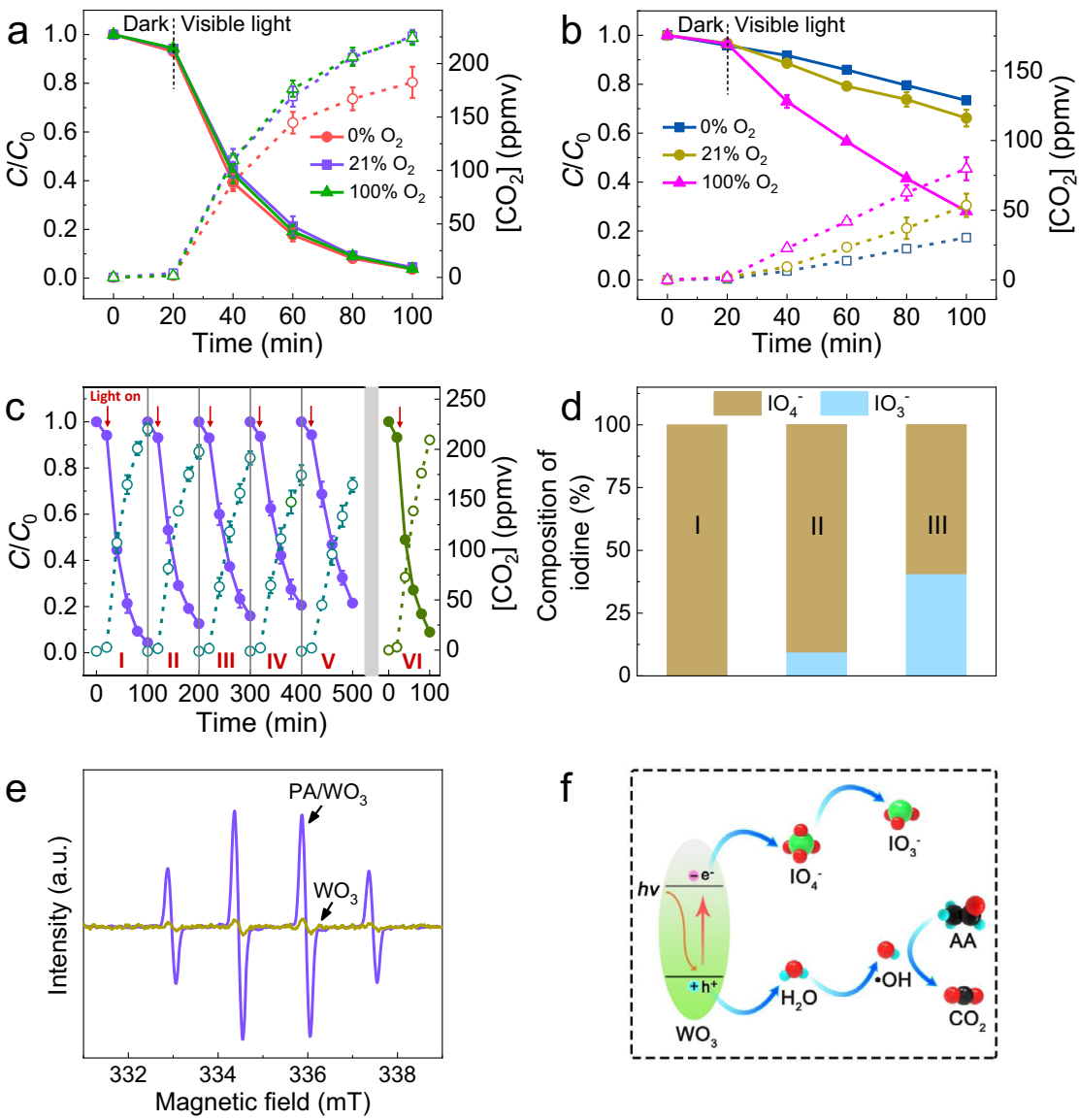

Fig. 5 Effects of $\mathbf{O}_{\mathbf{2}}$ and PA. Effect of $\mathrm{O}_{2}$ concentration on the PCD of acetaldehyde (AA) over a PA/WO $\mathrm{W}_{3}$ and $\mathbf{b}$ bare $W O_{3}$. $\mathbf{c}$ Repeated $P C D$ cycles of $A A$ degradation and the concurrent production of $\mathrm{CO}_{2}$ over PA/ $\mathrm{WO}_{3}(\mathrm{I}$, 1st cycle; II, 2nd cycle; III, 3rd cycle; IV, 4th cycle; V, 5th cycle), (VI) PA/WO 3 was regenerated after 5 th cycle. Error bars are defined as standard deviation. d Relative distribution of iodine species in $(\mathrm{I})$ fresh $\mathrm{PA} / \mathrm{WO} \mathrm{O}_{3}, \mathrm{PA} / \mathrm{WO}_{3}$ used after (II) 1st PCD cycle and (III) 5th PCD cycle of AA degradation in $\mathbf{c}: \mathrm{IO}_{4}{ }^{-}$(brown) and $\mathrm{IO}_{3}{ }^{-}$(cyan). e EPR spectra probing the photogeneration of $\bullet \mathrm{OH}$ adduct $(\bullet \mathrm{OH}-\mathrm{DMPO})$ in an aqueous catalyst slurry containing DMPO $\left(C_{0}=10 \mathrm{mM}\right)$. f Proposed PCD mechanism of AA. The dashed lines with open symbols represent the $\mathrm{CO}_{2}$ concentration generated from AA degradation. Experimental conditions: $[A A]_{0}=120$ ppmv; visible light $(\lambda>420 \mathrm{~nm})$ intensity of $2.2 \mathrm{~mW} / \mathrm{cm}^{2}$; sample amount of $50 \mathrm{mg}$; $\mathrm{RH} 65 \%$; reaction temperature of $30^{\circ} \mathrm{C}$.

On the other hand, as for the hole transfer part, the photocatalytic production of $\mathrm{OH}$ radicals is one of the primary mechanisms by which photocatalysts degrade VOCs. The ability of $\mathrm{PA} / \mathrm{WO}_{3}$ to produce $\bullet \mathrm{OH}$ was tested using a chemical trapping method using DMPO as a spin trap reagent ${ }^{57}$. After 10 min of blue LED irradiation $\left(460 \mathrm{~nm}, 2.0 \mathrm{~mW} / \mathrm{cm}^{2}\right)$, EPR signals for the $\bullet O H-D M P O$ adduct appeared as shown in Fig. 5e. Note that $\mathrm{PA} / \mathrm{WO}_{3}$ produced a prominent signal whereas bare $\mathrm{WO}_{3}$ generated an insignificant one. In general, bare $\mathrm{WO}_{3}$ is not an efficient photocatalyst because of the lower CB edge $\left(\sim 0.4 \mathrm{~V}_{\mathrm{NHE}}\right)^{58}$ that does not provide a sufficient potential to reduce $\mathrm{O}_{2}\left[E^{0}\left(\mathrm{O}_{2} / \mathrm{O}_{2} \bullet^{-}\right)=-0.33 \mathrm{~V}_{\mathrm{NHE}}\right.$ and $E^{0}$ $\left.\left(\mathrm{O}_{2} / \mathrm{HO}_{2} \bullet\right)=-0.05 \mathrm{~V}_{\mathrm{NHE}}\right]^{13,20}$. The inability of $\mathrm{O}_{2}$ to scavenge $\mathrm{CB}$ electrons in $\mathrm{WO}_{3}$ results in fast recombination and lower photocatalytic activity. After introducing PA, the periodate ions in the in situ formed surface water layer can scavenge CB electrons, which subsequently retards the charge recombination and makes more holes available for the production of $\bullet \mathrm{OH}$ that should be the primary oxidant in the PCD process. The photocatalytic oxidation mechanism (see Fig. 5f) can be briefly proposed as follows (Eqs. (1)-(5)):

$$
\begin{gathered}
\mathrm{WO}_{3}+\mathrm{h} v \rightarrow \mathrm{h}_{\mathrm{vb}}^{+}+\mathrm{e}_{\mathrm{cb}}^{-} \\
\left.\mathrm{HIO}_{4}(\mathrm{PA}) \rightarrow \mathrm{H}^{+}+\mathrm{IO}_{4}{ }^{-} \text {(in in situ water layer }\right)
\end{gathered}
$$

$$
\begin{gathered}
\mathrm{IO}_{4}^{-}+2 \mathrm{H}^{+}+2 \mathrm{e}_{\mathrm{cb}}^{-} \rightarrow \mathrm{IO}_{3}^{-}+\mathrm{H}_{2} \mathrm{O} \\
\mathrm{H}_{2} \mathrm{O}+\mathrm{h}^{+} \rightarrow \bullet \mathrm{OH}+\mathrm{H}^{+} \\
\mathrm{AA}+\bullet \mathrm{OH}+\mathrm{O}_{2} \rightarrow \rightarrow \mathrm{CO}_{2}
\end{gathered}
$$

Selective PCDs for hydrophilic vs. hydrophobic VOCs. Other VOCs including methanol $(\mathrm{MeOH})$, isopropanol (IPA), acetone (AT), n-pentane (C5), dichloromethane (DCM), n-chloropropane $\left(\mathrm{ClC}_{3}\right)$, and toluene $(\mathrm{Tol})$ were also tested for their PCDs by bare $\mathrm{WO}_{3}$ and $\mathrm{PA} / \mathrm{WO}_{3}$. As shown in Fig. 6a and b, the PCD behaviors are clearly different depending on the kind of target VOCs. Compared with bare $\mathrm{WO}_{3}, \mathrm{PA} / \mathrm{WO}_{3}$ increased the $\mathrm{PCD}$ rate constant $\left(k_{\mathrm{d}}\right)$ by $6.7,6.5$, and 7.5 times for the degradation of IPA, AT, and AA, respectively. Accordingly, the mineralization efficiency of IPA, $\mathrm{AT}$, and $\mathrm{AA}$ over $\mathrm{PA} / \mathrm{WO}_{3}$ was 5.2, 5.2, 4.2 times higher than that over bare $\mathrm{WO}_{3}$, respectively. Note that the $\mathrm{PCD}$ of $\mathrm{MeOH}$ was even more dramatically enhanced than that of $\mathrm{AA}$ on $\mathrm{PA} / \mathrm{WO}_{3}: k_{\mathrm{d}}$ for $\mathrm{MeOH}$ on $\mathrm{PA} / \mathrm{WO}_{3}\left(122.71 \times 10^{-3} \mathrm{~min}^{-1}\right)$ was 27.8 times higher than that of bare $\mathrm{WO}_{3}\left(k_{\mathrm{d}}=4.42 \times 10^{-3} \mathrm{~min}^{-1}\right)$. The PCDs of all the hydrophilic VOC molecules were markedly enhanced on PA/ $\mathrm{WO}_{3}$, which implies that they can be easily dissolved and 

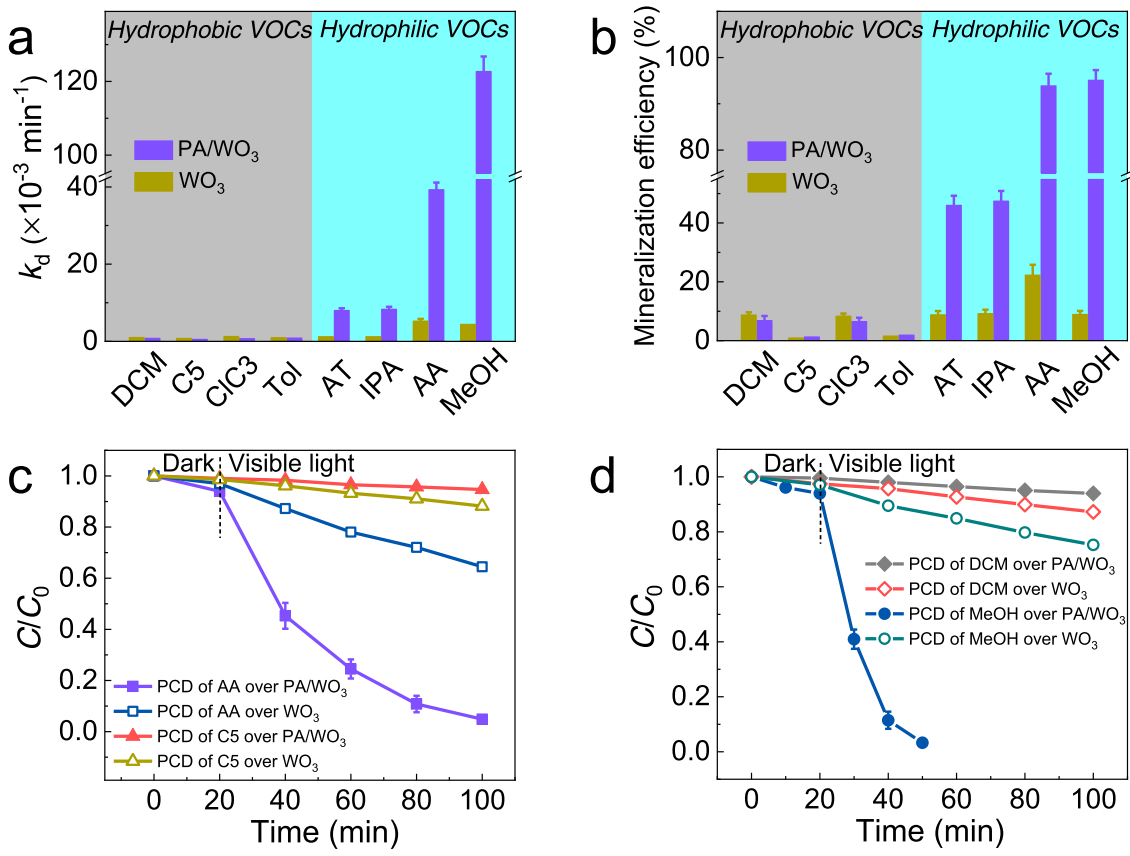

Fig. 6 Selective removal of hydrophilic volatile organic compounds (VOCs) over PA/ $\mathbf{W O}_{\mathbf{3}}$. a PCD rate constants $\left(k_{d}\right)$ and $\mathbf{b}$ the mineralization efficiencies of different $\mathrm{VOCs}$ over bare $\mathrm{WO}_{3}$ and $\mathrm{PA} / \mathrm{WO}_{3}$. PCD of the mixture of $\mathbf{c} \mathrm{AA}$ and $\mathrm{C} 5$ and $\mathbf{d} \mathrm{MeOH}$ and $\mathrm{DCM}$. Error bars are defined as standard deviation. Experimental conditions: $[\mathrm{VOC}]_{0}=120$ ppmv; visible light $(\lambda>420 \mathrm{~nm})$ intensity of $2.2 \mathrm{~mW} / \mathrm{cm}^{2}$; sample amount of $50 \mathrm{mg}$; RH $65 \%$; reaction temperature of $30^{\circ} \mathrm{C}$. AA acetaldehyde, IPA isopropanol, AT acetone, $\mathrm{MeOH}$ methanol, DCM dichloromethane, $\mathrm{C} 5 n$-pentane, $\mathrm{ClC}$, $n$-chloropropane, Tol toluene.

concentrated in the in situ formed surface water layer to facilitate their PCD. However, the situation was markedly different for the PCDs of hydrophobic VOC molecules. The PCD rates of DCM, C5, Tol, and $\mathrm{ClC}_{3}$ were very low over bare $\mathrm{WO}_{3}\left(k_{\mathrm{d}}<\right.$ $2.0 \times 10^{-3} \mathrm{~min}^{-1}$ ) and the corresponding mineralization efficiencies of these VOCs were lower than $10 \%$. Unlike the case of hydrophilic VOCs which exhibited the dramatic PA-enhanced effect, $\mathrm{PA} / \mathrm{WO}_{3}$ slightly hindered the PCDs of hydrophobic VOCs, compared with bare $\mathrm{WO}_{3}$. The water layer on $\mathrm{PA} / \mathrm{WO}_{3}$ should not dissolve hydrophobic VOC molecules and their PCDs should be limited under such conditions. The markedly contrasting PCD behaviors of $\mathrm{PA} / \mathrm{WO}_{3}$ between hydrophobic and hydrophilic VOCs should be ascribed to their different solubility in the in situ formed surface water layer.

The selective PCDs in VOC mixtures were also investigated under visible-light irradiation $(\lambda>420 \mathrm{~nm})$, as shown in Fig. $6 \mathrm{c}$ and $\mathrm{d}$. With $\mathrm{PA} / \mathrm{WO}_{3}$, more than $95 \%$ of AA could be removed in the AA/C5 mixture after 80 min of PCD while the concentration of $\mathrm{C} 5$ was almost unchanged. In the same manner, only $\mathrm{MeOH}$ could be selectively removed in $\mathrm{MeOH} / \mathrm{DCM}$ mixture. On the other hand, $\mathrm{PCD}$ over bare $\mathrm{WO}_{3}$ removed $35.5 \%$ of $\mathrm{AA}$ and $11.8 \%$ of $\mathrm{C} 5$ in $\mathrm{AA} / \mathrm{C} 5$ mixture in $80 \mathrm{~min} ; 24.7 \%$ of $\mathrm{MeOH}$ and $12.8 \%$ of DCM in $\mathrm{MeOH} / \mathrm{DCM}$ mixture. This clearly shows that $\mathrm{PA} / \mathrm{WO}_{3}$ has good selectivity for the degradation of hydrophilic VOCs while bare $\mathrm{WO}_{3}$ photocatalyst has much lower selectivity. It is quite clear that the presence of an in situ formed water layer on $\mathrm{PA} / \mathrm{WO}_{3}$ greatly facilitates the selective removal of hydrophilic VOC molecules while keeping hydrophobic VOCs intact in the hydrophilic-hydrophobic VOC mixture. As a result, the highly enhanced and selective removal of hydrophilic VOCs is enabled by the PA-treatment of $\mathrm{WO}_{3}$ photocatalyst which induces the in situ formation of the water layer on the catalyst surface. The role of in situ water layer formation on the PCDs of VOCs has not been previously recognized and needs to be further investigated for the selectivity control of VOCs degradation.

\section{Discussion}

The photocatalytic oxidation processes have been extensively investigated for the purification of polluted air and water. A variety of photocatalyst modification methods have been proposed and tested to improve the performance of PCD while many methods need complicated preparation procedures or costly materials such as noble metals. In this work, a very simple and inexpensive method of photocatalyst modification is proposed and demonstrated for the highly enhanced and selective degradation of VOCs. PA coating on photocatalysts proved to be an effective method to greatly enhance the photocatalytic activity of $\mathrm{WO}_{3}, \mathrm{BiVO}_{4}$, and $\mathrm{N}-\mathrm{TiO}_{2}$ for the degradation of $\mathrm{AA}$ (a common indoor air pollutant) under visible light. In particular, $\mathrm{PA} / \mathrm{WO}_{3}$ exhibited excellent performance in PCD of various hydrophilic VOCs. Under visible-light irradiation $(\lambda>420 \mathrm{~nm})$, the PCD rate constant $\left(k_{\mathrm{d}}\right)$ of IPA, AT, $\mathrm{AA}$, and $\mathrm{MeOH}$ over PA/ $/ \mathrm{WO}_{3}$ was 6.7, $6.5,7.5$, and 27.8 times higher than that of bare $\mathrm{WO}_{3}$. The hygroscopic property of PA enables the photocatalyst to form in situ surface water (self-wetting) layer in ambient air while the periodate ions in the in situ water layer serve as efficient electron acceptors on $\mathrm{WO}_{3}$ under visible light. In addition, PA formed surface complexes on $\mathrm{WO}_{3}$ surface not only to enhance the visible light absorption capacity but also to suppress the charge pair recombination by making PA scavenge CB electrons more efficiently. The multiple roles of PA induce a water layer on the photocatalyst surface, dissolve and concentrate hydrophilic VOCs in the water layer, and make more holes available to produce $\mathrm{OH}$ radicals. As a result, $\mathrm{PA} / \mathrm{WO}_{3}$ photocatalyst is even more active than Pt-loaded $\mathrm{WO}_{3}$ (a popular but expensive visible-light active photocatalyst) for the degradation of AA.

$\mathrm{PA}$ is proposed as a low-cost component to replace costly $\mathrm{Pt}$ cocatalyst for the removal of hydrophilic VOCs. PA is nonvolatile and comparatively nontoxic and its release into the air can be safely neglected. AA degraded by $\mathrm{PA} / \mathrm{WO}_{3}$ photocatalyst generated no detectable volatile byproducts. To check the possible 


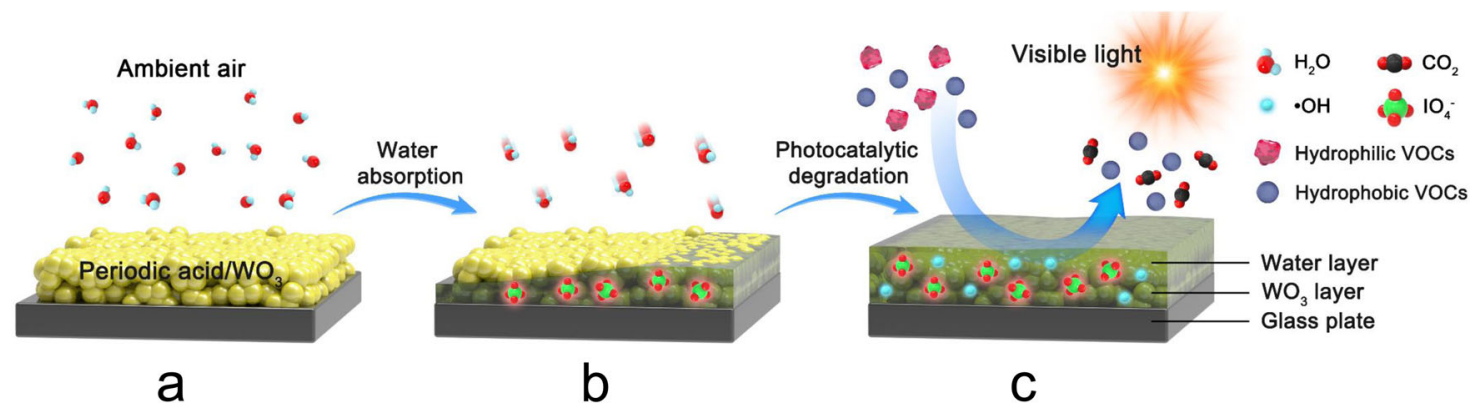

Fig. 7 Schematic illustration of the working mechanism of $\mathbf{P A} / \mathbf{W O} \mathbf{O}_{\mathbf{3}}$ photocatalysis for the selective $\mathbf{P C D}$. a $\mathrm{WO} \mathrm{O}_{3}$ is $c 0 a t e d$ with periodic acid ( $\mathrm{PA}$ ) to form $\mathrm{PA} \mathrm{WO}_{3}$. $\mathbf{b}$ In situ surface water layer is formed due to the hygroscopic property of $\mathrm{PA}$ in ambient air while the periodate ions (IO ${ }^{-}$) in the in situ water layer serve as efficient electron acceptors. c Under visible light, the photogenerated electrons are rapidly scavenged by $\mathrm{IO}_{4}{ }^{-}$while holes produce - $\mathrm{OH}$ radicals which subsequently degrade hydrophilic VOCs dissolved into the in situ water layer. However, hydrophobic VOCs remain intact during photocatalysis due to the "water barrier effect".

generation of volatile iodine species (e.g., $\mathrm{I}_{2}, \mathrm{HOI}$ ) from the transformation of PA during the PCD of $\mathrm{AA}$ on $\mathrm{PA} / \mathrm{WO}_{3}$, the treated air was absorbed by phenol solution $(1 \mathrm{mM})$ and analyzed for iodophenol (a product that should be generated from the reaction with volatile iodine species) by HPLC ${ }^{59}$. No iodophenol was detected, which indicated that no volatile iodine species was present in the treated air. No other gaseous organic products (e.g., FA, acetic acid) were found during the PCD of AA, which indicates the rapid mineralization of AA. The presence of a surface water layer can trap any hydrophilic intermediates and degrade them within the water layer without emitting them into the air phase. This self-wetting tri-phasic (air/water/catalyst) photocatalytic system facilitates the complete degradation of hydrophilic VOCs by providing the in situ water layer where the hydrophilic intermediates/byproducts are more efficiently retained and degraded in the aqueous phase whereas the common biphasic photocatalysis (air/catalyst) often generates gaseous intermediates.

From a practical point of view, a notable advantage is that the uptake of water vapor onto $\mathrm{PA} / \mathrm{WO}_{3}$ and the subsequent drying are reversible (as shown in the Supplementary video). This makes the wetting and drying process repeated depending on the humidity condition of the ambient air. As wetting a large surface is not convenient for practical applications, it is suggested that $\mathrm{PA} / \mathrm{WO}_{3}$ be employed as a replaceable filter component in air purifiers (especially for the removal of aldehydes such as AA and FA), not to be coated over the support with a large surface area. The reaction stoichiometry indicates that 5 moles of PA are needed to degrade 1 mole of $\mathrm{AA} \quad\left(\mathrm{CH}_{3} \mathrm{CHO}+5 \mathrm{IO}_{4}^{-} \rightarrow 2\right.$ $\left.\mathrm{CO}_{2}+5 \mathrm{IO}_{3}{ }^{-}\right)$. The cost of PA replacement should not be a problem because of its low price (99.9\% purity, $\sim 10.5 \$ / \mathrm{kg}$ in the USA). Our analysis showed that $40.7 \%$ of initial PA (25 mg PA in $50 \mathrm{mg} \mathrm{PA} / \mathrm{WO}_{3}$ ) was reduced to iodate along with mineralizing $0.29 \mathrm{mg}$ AA during five PCD cycles of AA (see Fig. 5d). This corresponds to the consumption of 1 mole PA for the degradation of 0.15 mole AA, which is close to the theoretical value $(5: 1)$. Based on this ratio, we estimate that $1 \mathrm{~g}$ PA is consumed to purify $317 \mathrm{~m}^{3}$ of indoor air contaminated with $[\mathrm{AA}]=90 \mu \mathrm{g} / \mathrm{m}^{3}(10$ times higher than the US EPA reference concentration for chronic inhalation exposure $\left.{ }^{60}, 9 \mu \mathrm{g} / \mathrm{m}^{3}\right)$. Moreover, the used filter can be washed with water and regenerated by replenishing PA or by recycling iodate back to periodate via electrochemical ${ }^{61}$ or other economical chemical oxidation methods. Alternatively, a photoelectrochemical (PEC) filter device that can regenerate in situ periodate as soon as it is converted into iodate under irradiation in the $\mathrm{PA} / \mathrm{WO}_{3}$ filter plans to be developed in a further study. To further investigate the effect of the geometric surface area of the coated photocatalyst, the PCD activity (for removing 500 ppbv $\mathrm{FA}$ in $1.5 \mathrm{~L}$ air) of $\mathrm{PA} / \mathrm{WO}_{3}$ was compared between the different geometric coating areas of $1 \mathrm{~cm}^{2}$ vs. $4 \mathrm{~cm}^{2}$ (see Supplementary Fig. 15). The PCD activity little decreased with decreasing the catalyst coating area from 4 to $1 \mathrm{~cm}^{2}$, which shows that the ratio of treated air volume to catalyst coating area can reach over $1.5 \mathrm{~L} / \mathrm{cm}^{2}$. This clearly demonstrates that $\mathrm{PA} / \mathrm{WO}_{3}$ has a good capacity in purifying large volumes of air. In practical applications, this ratio is expected to be further enhanced by optimizing the catalyst dosage and coating thickness. Specific design parameters (e.g., airflow rate, catalyst dosage, thickness and area of catalyst coating, etc.) need to be carefully adjusted according to the actual application purpose. These engineering parameters remain to be investigated in future works. It is worth noting that the $\mathrm{PA} / \mathrm{WO}_{3}$ photocatalyst demonstrated good applicability for a wide range of VOC concentrations (500 ppbv-700 ppmv).

On the other hand, the inability of $\mathrm{PA} / \mathrm{WO}_{3}$ to remove hydrophobic VOCs (e.g., DCM, C5, $\mathrm{ClC}_{3}$, and $\mathrm{Tol}$ ) is a serious limitation for general purpose applications. However, its ability to degrade hydrophilic VOCs selectively against hydrophobic VOCs can be exploited in a specific application (see Fig. 7). In addition, the in situ formed water layer can protect the photocatalyst surface from fouling with inhibiting the deposition of hydrophobic components (e.g., indoor particulate matters like cooking particles, various VOCs containing halogen/phosphorus/silicon found in indoor environments $)^{62-64}$. As a viable strategy for exploiting in situ water layer formation in ambient air photocatalysis, the PA/photocatalyst may be combined in a hybrid air treatment system where hydrophilic VOCs (that can be rapidly degraded by photocatalysis) are selectively degraded by the PA/photocatalyst and then hydrophobic VOCs (that are more recalcitrant against photocatalysis) are removed by other methods such as adsorption and thermal catalysis. Such an approach combines the advantages of various technologies to develop a more efficient and economical method of controlling VOCs.

\section{Methods}

Materials. The chemicals used in this study are as follows: Tungsten oxide $\left(\mathrm{WO}_{3}\right.$, nanopowder, Sigma-Aldrich), titanium dioxide $\left(\mathrm{TiO}_{2}, \mathrm{P} 25\right.$, nanopowder, Evonik), bismuth vanadate $\left(\mathrm{BiVO}_{4}\right.$, nanopowder, Alfa Aesar), $\mathrm{PA}\left(\mathrm{HIO}_{4} \cdot 2 \mathrm{H}_{2} \mathrm{O}, \geq 99.0 \%\right.$, Sigma-Aldrich), iodic acid ( $\mathrm{HIO}_{3}, \geq 99.5 \%$, Sigma-Aldrich), sodium periodate $\left(\mathrm{NaIO}_{4}, \geq 99.8 \%\right.$, Sigma-Aldrich), sodium iodate $\left(\mathrm{NaIO}_{3}, 99 \%\right.$, Sigma-Aldrich), sodium iodide (NaI, $\geq 99.0 \%$, Sigma-Aldrich), chloroplatinic acid $\left(\mathrm{H}_{2} \mathrm{PtCl}_{6} \cdot x \mathrm{H}_{2} \mathrm{O}\right.$, $\geq 99.9 \%$, Sigma-Aldrich), $\mathrm{MeOH}\left(\mathrm{CH}_{3} \mathrm{OH}, 99.9 \%\right.$, Samchun Chemicals), IPA $\left(\left(\mathrm{CH}_{3}\right)_{2} \mathrm{CHOH}, 99.5 \%\right.$, Sigma-Aldrich), AT $\left(\mathrm{CH}_{3} \mathrm{COCH}_{3}, 99.98 \%\right.$, Burdick Jackson), DCM $\left(\mathrm{CH}_{2} \mathrm{Cl}_{2}, \geq 99.8 \%\right.$, Sigma-Aldrich), C5 $\left(\mathrm{CH}_{3}\left(\mathrm{CH}_{2}\right)_{3} \mathrm{CH}_{3}, \geq 99.0\right.$, Sigma-Aldrich), $\mathrm{ClC}_{3}\left(\mathrm{CH}_{3} \mathrm{CH}_{2} \mathrm{CH}_{2} \mathrm{Cl}, 99 \%\right.$, Alfa Aesar), 5,5-dimethyl-1-pyrroline- $N$-oxide (DMPO, $\geq 98.0$, Sigma-Aldrich). Tol (300 ppmv, $\mathrm{N}_{2}$ balance), AA (1000 ppmv, $\mathrm{N}_{2}$ balance), FA (100 ppmv, $\mathrm{N}_{2}$ balance), high-purity synthetic air $\left(79 \% \mathrm{~N}_{2} / 21 \% \mathrm{O}_{2}\right)$ were purchased from Deokyang Company. All chemicals were of 
reagent grade and used as received without further purification. Ultrapure deionized water $(18 \mathrm{M} \Omega \mathrm{cm})$ prepared using a Millipore system was used.

Preparation of photocatalyst materials. Commercial $\mathrm{WO}_{3}$ powder sample was treated with PA. Typically, $0.25 \mathrm{~g} \mathrm{WO}_{3}$ was dispersed in $10 \mathrm{~mL} 0.11 \mathrm{~mol} / \mathrm{L} \mathrm{PA}$ solution under sonication. The mixture was stirred at room temperature for $12 \mathrm{~h}$, and the obtained suspension was completely dried in an oven at $80^{\circ} \mathrm{C}$. To compare with $\mathrm{PA} / \mathrm{WO}_{3}$ sample, control $\mathrm{WO}_{3}$ samples that were treated using $\mathrm{NaIO}_{4}, \mathrm{NaIO}_{3}$, $\mathrm{HIO}_{3}$, or $\mathrm{NaI}$ as an alternative reagent were also prepared under the same experimental conditions.

Two other visible light photocatalysts of $\mathrm{N}$-doped $\mathrm{TiO}_{2}\left(\mathrm{~N}-\mathrm{TiO}_{2}\right)$ and $\mathrm{BiVO}_{4}$ were also treated with PA and compared with $\mathrm{WO}_{3}$ for the effects of PA treatment. $\mathrm{N}-\mathrm{TiO}_{2}$ was prepared by high-temperature nitridation of $\mathrm{TiO}_{2}{ }^{65}$ : commercial P25 powder was treated in a tubular furnace at $500^{\circ} \mathrm{C}$ under $\mathrm{NH}_{3}$ gas flow $(150 \mathrm{~mL} /$ min) for $5 \mathrm{~h}$. Then, $0.25 \mathrm{~g}$ of $\mathrm{N}-\mathrm{TiO}_{2}$ and $\mathrm{BiVO}_{4}$ were treated with $0.11 \mathrm{~mol} / \mathrm{L} \mathrm{PA}$ solution under the same condition as that of $\mathrm{WO}_{3}$. In addition, $\mathrm{Pt} / \mathrm{WO}_{3}$ was prepared using a photodeposition method as another standard visible light photocatalyst ${ }^{23,27}$. Typically, an aqueous suspension of $\mathrm{WO}_{3}(0.5 \mathrm{~g} / \mathrm{L})$ was irradiated with a $200 \mathrm{~W}$ mercury lamp for $30 \mathrm{~min}$ in the presence of chloroplatinic acid as a Pt precursor and $\mathrm{MeOH}(1 \mathrm{~mol} / \mathrm{L})$ as an electron donor. The amount of platinum loading was fixed at $1 \mathrm{wt} \%$ for $\mathrm{WO}_{3}$. The resulting $\mathrm{Pt} / \mathrm{WO}_{3}$ powder was collected by filtration and washed with deionized water.

PCD experiments. The PCD of VOCs was conducted under visible light irradiation from a mercury lamp (custom-made), which was filtered through a 420-nm cutoff $(\lambda>420 \mathrm{~nm})$ filter. The filtered light intensity on the photocatalyst was measured to be $2.2 \mathrm{~mW} / \mathrm{cm}^{2}$ by a power meter (Newport 1918-R). A closedcirculation glass reactor $(300 \mathrm{~mL}$ ) with a quartz window (a radius of $3 \mathrm{~cm}$ ) was used (see Supplementary Fig. 1). A magnetic bar was placed at the bottom of the glass reactor to stir the air. The reactor was connected to a gas chromatograph (GC-Agilent 6890 Plus) equipped with a methane converter, a Porapak R column, an automatic sampling valve using an air actuator, and a flame ionization detector. The relative humidity (RH) was adjusted to $\sim 65 \%$ by bubbling air through a stainless-steel bottle containing deionized water. A heating device was used to maintain the temperature of the photocatalytic reactor at $\sim 30^{\circ} \mathrm{C}$. To test the airtightness of the reactor, it was filled with high-purity synthetic air $\left(79 \% \mathrm{~N}_{2} / 21 \%\right.$ $\left.\mathrm{O}_{2}\right)$ and exposed to ambient air. A negligible increase in $\mathrm{CO}_{2}(<4 \mathrm{ppmv}$ within $60 \mathrm{~min}$ ) was detected, indicating good airtightness of the reactor system.

Photocatalyst powder $(50 \mathrm{mg}$ ) was dispersed in water in a quartz glass sink which possessed a $2 \mathrm{~cm} \times 2 \mathrm{~cm}$ groove to hold the catalyst component. The catalyst slurry was completely dried and placed in the reactor for PCD tests. Before each PCD experiment, the glass reactor was purged with high-purity synthetic air $(79 \%$ $\mathrm{N}_{2} / 21 \% \mathrm{O}_{2}$ ) and irradiated under the mercury lamp or LED lamp to degrade any organic impurities remaining on the photocatalyst surface. The cleaning irradiation continued until the photogeneration of $\mathrm{CO}_{2}$ was not detected.

Target VOCs tested in this study include FA, AA, IPA, AT, MeOH, DCM, C5, $\mathrm{ClC}_{3}$, and Tol. AA or Tol was introduced into the photocatalytic reactor through diluting the standard gas ( $1000 \mathrm{ppmv} \mathrm{AA}, 300 \mathrm{ppmv} \mathrm{Tol}$ in $\mathrm{N}_{2}$ ). For other VOCs (IPA, AT, MeOH, DCM, C5, or $\mathrm{ClC}_{3}$ ), a calculated amount of each liquid sample was injected into the reactor and subsequently vaporized into the gas phase. The initial concentration of VOCs was adjusted to 120 ppmv. After 20 min equilibration for complete dispersion and pre-adsorption of VOCs on the photocatalyst surface, the mercury lamp was turned on to initiate the PCD process. The removal of each VOC and the accompanying $\mathrm{CO}_{2}$ production was monitored in real-time by using a GC. All the control experiments were conducted under the same condition.

The PCD experiments of FA were carried out using a bigger reactor $(1.5 \mathrm{~L})$ instead of a $300 \mathrm{~mL}$ reactor to demonstrate the photocatalytic air treatment on a larger scale. A $460 \mathrm{~nm}$-emitting LED (Luna Fiber Optic Korea, ICN14D-096) was employed as a light source. Photocatalyst powder $(1,10,50$, and $100 \mathrm{mg})$ was dispersed in water in a quartz glass groove $(2 \mathrm{~cm} \times 2 \mathrm{~cm})$, which was dried and placed in the PCD reactor. Before each PCD test, the glass reactor was purged with high-purity synthetic air $\left(79 \% \mathrm{~N}_{2} / 21 \% \mathrm{O}_{2}\right)$ and irradiated under an LED lamp to clean the photocatalyst surface. FA was introduced into the reactor through a mass flow controller regulating the standard gas ( $100 \mathrm{ppmv} F A$ in $\mathrm{N}_{2}$ ) flow. The initial concentration of FA was adjusted at $500 \mathrm{ppbv}$, which is much lower than that of other VOCs $(120 \mathrm{ppmv})$. This represents a more realistic test condition where FA is present in an indoor air environment. A photoacoustic gas monitor (LumaSense, INNOVA 1412i) was used to measure the concentrations of FA.

Analysis and characterizations. X-ray diffraction (XRD) patterns of the photocatalyst samples were collected using an X-ray diffractometer (PANalytical X'Pert diffractometer) using $\mathrm{Cu} \mathrm{Ka}$ irradiation. Nitrogen adsorption-desorption isotherms were recorded at $77 \mathrm{~K}$ by using a BELSORP-MINI II (BEL-Japan, Inc.). Before the measurement, the sample was degassed at $423 \mathrm{~K}$ overnight. The specific surface area was calculated via a multipoint BET analysis of the $\mathrm{N}_{2}$ adsorption isotherm. FE-SEM images were taken by JSM-7800 F prime microscope at National Institute for Nanomaterials Technology (NINT, Pohang, Korea). X-ray photoelectron spectroscopy (XPS) was conducted using a Thermo Scientific K-Alpha XPS with $\mathrm{Al} \mathrm{Ka}(h v=1486.6 \mathrm{eV})$ as the excitation source. Fourier transform infrared (FTIR) spectra were obtained using an attenuated total reflectance-FTIR (ATR-FTIR) spectrometer (Thermo Scientific Nicolet iS50 FT-IR/ATR). Diffuse reflectance UV-visible absorption spectroscopy (DRS) was conducted using a spectrophotometer (Shimadzu UV-2401PC).

The quantitative analysis of iodine species, mainly iodate $\left(\mathrm{IO}_{3}{ }^{-}\right)$and periodate $\left(\mathrm{IO}_{4}^{-}\right)$was carried out using HPLC (Agilent 1100) equipped with an Agilent Zorbax 300SB C-18 column and a diode-array detector. The typical eluent consisted of a binary mixture of $0.1 \%(\mathrm{v} / \mathrm{v})$ phosphoric acid aqueous solution and acetonitrile (typically 70:30 v/v). The photocatalytic production of $\mathrm{OH}$ radicals was confirmed using an electron paramagnetic resonance (EPR) spin trapping method (ELEXYS E580, Bruker Co.): $10 \mathrm{mM} \mathrm{DMPO} \mathrm{as} \mathrm{a} \mathrm{spin-trapping} \mathrm{agent} \mathrm{was} \mathrm{added} \mathrm{to}$ the aqueous catalyst slurry under irradiation of blue LED (Luna Fiber Optic Korea CWL $460 \mathrm{~nm}, 2.0 \mathrm{~mW} / \mathrm{cm}^{2}$ ). Real-time monitoring of the dynamic movement of catalyst particles and in situ formed water layer in the $\mathrm{PA} / \mathrm{WO}_{3}$ system was performed using a Leica DM 5000 B microscope equipped with a Leica DFC420 camera (Leica, Wetzlar, Germany).

In situ DRIFTS was performed using an FT-IR spectrometer (PerkinElmer, USA) equipped with a diffuse-reflectance cell (PIKE) with a ZnSe window. The catalyst sample was placed in the cell and pretreated at $100^{\circ} \mathrm{C}$ to eliminate the effects of adsorbed water. AA of $300 \mathrm{ppmv}$ was introduced into the cell by diluting the standard gas ( 1000 ppmv AA in $\mathrm{N}_{2}$ ) with air. The $\mathrm{RH}$ was adjusted by bubbling the air through a stainless-steel bottle containing deionized water. In situ DRIFTS spectra were collected after exposing the samples to the flowing stream for $10 \mathrm{~s}, 1$, 3 , and $5 \mathrm{~min}$, respectively.

Computational details. Density function theory (DFT) calculations were performed by using the CP2K package ${ }^{66}$. PBE functional ${ }^{67}$ with Grimme D3 correction $^{68}$ was used to describe the system. Unrestricted Kohn-Sham DFT has been used as the electronic structure method in the framework of the Gaussian and plane waves method ${ }^{69}$. The Goedecker-Teter-Hutter (GTH) pseudopotentials ${ }^{70}$, DZVPMOLOPT-GTH basis sets ${ }^{69}$ were utilized to describe the molecules. A planewave energy cut-off of $500 \mathrm{Ry}$ has been employed.

The charge density difference is defined as Eq. (6):

$$
\Delta \rho=\rho_{\mathrm{mol}} /{ }_{\text {sur }}-\rho_{\text {mol }}-\rho_{\text {sur }}
$$

where $\rho_{\text {mol }} /$ sur,$\rho_{\text {mol, }}$ and $\rho_{\text {sur }}$ are the electron density of the molecule adsorbed on the surface, the molecule, and the surface, respectively. The BE is defined as Eq. (7):

$$
E_{\mathrm{b}}=E_{\mathrm{mol}} /{ }_{\mathrm{sur}}-E_{\mathrm{mol}}-E_{\mathrm{sur}}
$$

where $E_{\mathrm{mol}} /_{\text {sur }}, E_{\mathrm{mol}}$ and $E_{\mathrm{sur}}$ are the energy of the molecule adsorbed on the surface, the molecule, and the surface, respectively.

Calculation of apparent quantum efficiency (AQE). For the measurement of AQE, two monochromatic LEDs (Luna Fiber Optic Korea, $2.0 \mathrm{~mW} / \mathrm{cm}^{2}$ ) which emit light at ca. 365 and $460 \mathrm{~nm}$ were used in the PCD of AA. Except for the light source, all the conditions were the same as that in the PCD tests using the mercury lamp. The AQE of AA degradation was indirectly calculated based on the $\mathrm{CO}_{2}$ generation rate within $40 \mathrm{~min}$ PCD reaction to rule out the effect of AA adsorption on the catalyst surface and reactor surface. The PCD of AA can be divided into the following two half-reactions (Eqs. (8)-(10)).

$$
\text { Oxidation: } \mathrm{CH}_{3} \mathrm{CHO}+3 \mathrm{H}_{2} \mathrm{O} \rightarrow 2 \mathrm{CO}_{2}+10 \mathrm{H}^{+}+10 \mathrm{e}^{-}
$$

Reduction: $2.5 \mathrm{O}_{2}+10 \mathrm{H}^{+}+10 \mathrm{e}^{-} \rightarrow 5 \mathrm{H}_{2} \mathrm{O}$

$$
\text { Overall: } \mathrm{CH}_{3} \mathrm{CHO}+2.5 \mathrm{O}_{2} \rightarrow 2 \mathrm{CO}_{2}+2 \mathrm{H}_{2} \mathrm{O}
$$

The full degradation of an AA molecule leads to the production of two $\mathrm{CO}_{2}$ molecules, which is a 10-electron oxidation. Therefore, the production of one $\mathrm{CO}_{2}$ molecule needs a 5-electron oxidation, which should consume 5 photons: the AQE estimated from the $\mathrm{CO}_{2}$ production measurement is based on this stoichiometry. The number of incident photons indicates the total number of photons reaching the surface of the catalyst during the reaction time, which were calculated by Eq (11). The number of reacted photons indicates the number of photons that are utilized in transforming AA molecules into $\mathrm{CO}_{2}$, which was calculated by Eq. (12). The AQE was calculated by Eq. (12)/Eq. (11). Such estimation of AQE is based on the assumption that AA molecules are fully mineralized to $\mathrm{CO}_{2}$ with the negligible generation of intermediates. As the PCD of AA on $\mathrm{PA} / \mathrm{WO}_{3}$ accompanied the stoichiometric production of $\mathrm{CO}_{2}$ (see Figs. 1, 3, 5), the formation of intermediates (if any) should be negligible in terms of the carbon mass balance.

$$
\begin{gathered}
\text { Number of incident photons }=\frac{E \lambda A t}{h c} \\
\text { Number of reacted photons }=5 R_{\mathrm{CO}_{2}} N_{\mathrm{A}} t \\
\mathrm{AQE}=\frac{\text { Number of reacted photons }}{\text { Number of incident photons }} \times 100 \%
\end{gathered}
$$

where $E$ is the intensity of LED $\left(\mathrm{mW} / \mathrm{cm}^{2}\right) ; \lambda$ is the wavelength of LED; $A$ is the irradiation area of photocatalysts; $t$ is the illumination/reaction time (40 $\mathrm{min}) ; h$ is 
the Planck constant, $6.626 \times 10^{-34} \mathrm{Js} ; c$ is the velocity of light; $R_{\mathrm{CO} 2}$ is the $\mathrm{CO}_{2}$ generation rate $(\mathrm{mol} / \mathrm{min})$; and $N_{\mathrm{A}}$ is the Avogadro constant, $6.02 \times 10^{23} / \mathrm{mol}$.

\section{Data availability}

Source data are provided with this paper. All data are also available from the corresponding author on request.

Received: 24 December 2020; Accepted: 1 October 2021; Published online: 29 October 2021

\section{References}

1. Vandyck, T. et al. Air quality co-benefits for human health and agriculture counterbalance costs to meet Paris Agreement pledges. Nat. Commun. 9, 4939 (2018).

2. Chen, W. Y., Jiang, X. F., Lai, S. N., Peroulis, D. \& Stanciu, L. Nanohybrids of a MXene and transition metal dichalcogenide for selective detection of volatile organic compounds. Nat. Commun. 11, 1302 (2020).

3. Weon, $\mathrm{S}$. et al. Active $\{001\}$ facet exposed $\mathrm{TiO}_{2}$ nanotubes photocatalyst filter for volatile organic compounds removal: From material development to commercial indoor air cleaner application. Environ. Sci. Technol. 52, 9330-9340 (2018).

4. Sircar, S. Basic research needs for design of adsorptive gas separation processes. Ind. Eng. Chem. Res. 45, 5435-5448 (2006).

5. Zhu, L. L., Shen, D. K. \& Luo, K. H. A critical review on VOCs adsorption by different porous materials: Species, mechanisms and modification methods. J. Hazard. Mater. 389, 122102 (2020).

6. Carter, E. M., Katz, L. E., Speitel, G. E. \& Ramirez, D. Gas-phase formaldehyde adsorption isotherm studies on activated carbon: Correlations of adsorption capacity to surface functional group density. Environ. Sci. Technol. 45, 6498-6503 (2011).

7. Chen, X. X. et al. Photocatalytic oxidation of methane over silver decorated zinc oxide nanocatalysts. Nat. Commun. 7, 12273 (2016).

8. Xiao, S. N. et al. A chloroplast structured photocatalyst enabled by microwave synthesis. Nat. Commun. 10, 1570 (2019).

9. Li, Y. X. et al. Constructing solid-gas-interfacial fenton reaction over alkalinized- $\mathrm{C}_{3} \mathrm{~N}_{4}$ photocatalyst to achieve apparent quantum yield of $49 \%$ at 420 nm. J. Am. Chem. Soc. 138, 13289-13297 (2016).

10. Kim, H. I. et al. Robust co-catalytic performance of nanodiamonds loaded on $\mathrm{WO}_{3}$ for the decomposition of volatile organic compounds under visible light. ACS Catal. 6, 8350-8360 (2016).

11. Mamaghani, A. H., Haghighat, F. \& Lee, C. S. Photocatalytic oxidation technology for indoor environment air purification: the state-of-the-art. Appl. Catal. B Environ. 203, 247-269 (2017).

12. Yin, R. L. et al. Near-infrared light to heat conversion in peroxydisulfate activation with $\mathrm{MoS}_{2}$ : A new photo-activation process for water treatment. Water Res. 190, 116720 (2021)

13. Weon, S., He, F. \& Choi, W. Status and challenges in photocatalytic nanotechnology for cleaning air polluted with volatile organic compounds: visible light utilization and catalyst deactivation. Environ. Sci. Nano 6, 3185-3214 (2019).

14. Teoh, W. Y., Scott, J. A. \& Amal, R. Progress in heterogeneous photocatalysis: From classical radical chemistry to engineering nanomaterials and solar reactors. J. Phys. Chem. Lett. 3, 629-639 (2012)

15. Nimlos, M. R., Wolfrum, E. J., Brewer, M. L., Fennell, J. A. \& Bintner, G. Gasphase heterogeneous photocatalytic oxidation of ethanol: pathways and kinetic modeling. Environ. Sci. Technol. 30, 3102-3110 (1996).

16. Ravelli, D., Dondi, D., Fagnoni, M. \& Albini, A. Photocatalysis. A multifaceted concept for green chemistry. Chem. Soc. Rev. 38, 1999-2011 (2009).

17. Jeon, T. H. et al. $\operatorname{Ag}(\mathrm{I})$ ions working as a hole-transfer mediator in photoelectrocatalytic water oxidation on $\mathrm{WO}_{3}$ film. Nat. Commun. 11, 967 (2020).

18. Shi, X. J. et al. Efficient photoelectrochemical hydrogen production from bismuth vanadate-decorated tungsten trioxide helix nanostructures. Nat. Commun. 5, 4775 (2014)

19. Dong, P. Y., Hou, G. H., Xi, X. U., Shao, R. \& Dong, F. $\mathrm{WO}_{3}$-based photocatalysts: morphology control, activity enhancement and multifunctional applications. Environ. Sci. Nano 4, 539-557 (2017).

20. Chen, M., Zhao, J. J., Huang, X. B., Wang, Y. R. \& Xu, Y. M. Improved performance of $\mathrm{BiVO}_{4}$ via surface-deposited magnetic $\mathrm{CuFe}_{2} \mathrm{O}_{4}$ for phenol oxidation and $\mathrm{O}_{2}$ reduction and evolution under visible light. ACS Appl. Mater. Interfaces 11, 45776-45784 (2019).

21. Arai, T. et al. Efficient complete oxidation of acetaldehyde into $\mathrm{CO}_{2}$ over $\mathrm{CuBi}_{2} \mathrm{O}_{4} / \mathrm{WO}_{3}$ composite photocatalyst under visible and UV light irradiation. J. Phys. Chem. C 111, 7574-7577 (2007).
22. Irie, H., Miura, S., Kamiya, K. \& Hashimoto, K. Efficient visible light-sensitive photocatalysts: grafting $\mathrm{Cu}(\mathrm{II})$ ions onto $\mathrm{TiO}_{2}$ and $\mathrm{WO}_{3}$ photocatalysts. Chem Phys. Lett. 457, 202-205 (2008).

23. Abe, R., Takami, H., Murakami, N. \& Ohtani, B. Pristine simple oxides as visible light driven photocatalysts: highly efficient decomposition of organic compounds over platinum-loaded tungsten oxide. J. Am. Chem. Soc. 130, 7780-7781 (2008)

24. Jiang, K. et al. Highly selective oxygen reduction to hydrogen peroxide on transition metal single atom coordination. Nat. Commun. 10, 3997 (2019).

25. Loget, G. et al. Tailoring the photoelectrochemistry of catalytic metalinsulator-semiconductor (MIS) photoanodes by a dissolution method. Nat. Commun. 10, 3522 (2019).

26. Choi, C. H. et al. Tuning selectivity of electrochemical reactions by atomically dispersed platinum catalyst. Nat. Commun. 7, 10922 (2016).

27. Kim, J., Lee, C. W. \& Choi, W. Platinized $\mathrm{WO}_{3}$ as an environmental photocatalyst that generates $\mathrm{OH}$ radicals under visible light. Environ. Sci. Technol. 44, 6849-6854 (2010).

28. $\mathrm{Li}, \mathrm{Y}$. H. et al. Local atomic structure modulations activate metal oxide as electrocatalyst for hydrogen evolution in acidic water. Nat. Commun. 6, 8064 (2015).

29. Pelaez, M. et al. A review on the visible light active titanium dioxide photocatalysts for environmental applications. Appl. Catal. B Environ. 125, 331-349 (2012).

30. Mo, J. H., Zhang, Y. P. \& Xu, Q. J. Effect of water vapor on the by-products and decomposition rate of ppb-level toluene by photocatalytic oxidation. Appl. Catal. B Environ. 132, 212-218 (2013).

31. Annapragada, R., Leet, R., Changrani, R. \& Raupp, G. B. Vacuum photocatalytic oxidation of trichloroethylene. Environ. Sci. Technol. 31, 1898-1901 (1997)

32. He, F., Muliane, U., Weon, S. \& Choi, W. Substrate-specific mineralization and deactivation behaviors of $\mathrm{TiO}_{2}$ as an air-cleaning photocatalyst. Appl. Catal. B Environ. 275, 119145 (2020)

33. Lucas, H. J. \& Stewart, W. T. Oxidation of alginic acid by periodic acid. J. Am Chem. Soc. 62, 1792-1796 (1940)

34. Marinetti, G., Berry, J. F., Rouser, G. \& Stotz, E. Studies on the structure of sphingomyelin. II. Performic and periodic acid oxidation studies. J. Am. Chem. Soc. 75, 313-315 (1953).

35. Choi, Y. et al. Activation of periodate by freezing for the degradation of aqueous organic pollutants. Environ. Sci. Technol. 52, 5378-5385 (2018).

36. Lide, D. R. CRC Handbook of Chemistry and Physics 77th edn (CRC Press, 1996).

37. Sharma, K. R. \& Noyes, R. M. Oscillations in chemical systems. 13. A detailed molecular mechanism for the Bray-Liebhafsky reaction of iodate and hydrogen peroxide. J. Am. Chem. Soc. 98, 4345-4361 (1976).

38. Theakston, F. (ed.) Air Quality Guidelines for Europe, European Series, No. 91 2nd edn (WHO Regional Publications, 1987, 2000).

39. Shen, F. P. et al. Edge-tailored graphene oxide nanosheet-based field effect transistors for fast and reversible electronic detection of sulfur dioxide. Nanoscale 5, 537-540 (2013).

40. Obee, T. N. \& Hay, S. O. Effects of moisture and temperature on the photooxidation of ethylene on titania. Environ. Sci. Technol. 31, 2034-2038 (1997).

41. Verdejo, R., Lamoriniere, S., Cottam, B., Bismarck, A. \& Shaffer, M. Removal of oxidation debris from multi-walled carbon nanotubes. ChemComm $\mathbf{5}$ 513-515 (2007).

42. Malayeri, M., Haghighat, F. \& Lee, C. S. Modeling of volatile organic compounds degradation by photocatalytic oxidation reactor in indoor air: a review. Build. Environ. 154, 309-323 (2019).

43. Weissberger, A., Riddick, J. A., Bunger, W. B. \& Sakano, T. K. Techniques of Chemistry 4th edn, Vol. II. Organic Solvents 327 (John Wiley and Sons, 1985)

44. Fraters, B. D., Amrollahi, R. \& Mul, G. How Pt nanoparticles affect $\mathrm{TiO}_{2}$ induced gas-phase photocatalytic oxidation reactions. J. Catal. 324, 119-126 (2015).

45. Anand, M., Farooqui, S. A., Singh, J., Singh, H. \& Sinha, A. K. Mechanistic in operando FT-IR studies for hydroprocessing of triglycerides. Catal. Today 309, 11-17 (2018)

46. Kanokkantapong, V., Marhaba, T. F., Panyapinyophol, B. \& Pavasant, P. FTIR evaluation of functional groups involved in the formation of haloacetic acids during the chlorination of raw water. J. Hazard. Mater. 136, 188-196 (2006).

47. Chen, W., Tong, U. S., Zeng, T., Streb, C. \& Song, Y. F. Reversible photodimerization of coumarin-modified Wells-Dawson anions. J. Mater. Chem. C 3, 4388-4393 (2015)

48. Kun, R. et al. Preparation and characterization of mesoporous N-doped and sulfuric acid treated anatase $\mathrm{TiO}_{2}$ catalysts and their photocatalytic activity under UV and Vis illumination. J. Solid State Chem. 182, 3076-3084 (2009)

49. Wang, X. C. et al. Probing of photocatalytic surface sites on $\mathrm{SO}_{4}{ }^{2-} / \mathrm{TiO}_{2}$ solid acids by in situ FT-IR spectroscopy and pyridine adsorption. J. Photochem. Photobiol. A 179, 339-347 (2006). 
50. Cui, H. Q., Cao, Y., Jing, L. Q., Luan, Y. B. \& Li, N. Effects of inorganic acid modification on photocatalytic performance of $\mathrm{TiO}_{2}$ and its activityenhanced mechanism related to adsorbed $\mathrm{O}_{2}$. ChemPlusChem 79, 318-324 (2014).

51. Zhang, G., Kim, G. \& Choi, W. Visible light driven photocatalysis mediated via ligand-to-metal charge transfer (LMCT): an alternative approach to solar activation of titania. Energy Environ. Sci. 7, 954-966 (2014).

52. Liu, J. M. et al. Enhanced visible-light photocatalytic activity of carbonatedoped anatase $\mathrm{TiO}_{2}$ based on the electron-withdrawing bidentate carboxylate linkage. Appl. Catal. B Environ. 202, 642-652 (2017).

53. Xu, B. Y. et al. An efficient visible-light photocatalyst made from a nonpolar layered semiconductor by grafting electron-withdrawing organic molecules to its surface. Chem Comm 52, 13507-13510 (2016).

54. Kulish, V. V., Malyi, O. I., Persson, C. \& Wu, P. Adsorption of metal adatoms on single-layer phosphorene. Phys. Chem. Chem. Phys. 17, 992-1000 (2015).

55. Filho, B. M. C. \& Vilar, V. J. P. Strategies for the intensification of photocatalytic oxidation processes towards air streams decontamination: a review. Chem. Eng. J. 19, 123531 (2019).

56. Li, H. H., Yin, S., Wang, Y. H. \& Sato, T. Persistent fluorescence-assisted $\mathrm{TiO}_{2-}$ ${ }_{x} \mathrm{~N}_{y}$-based photocatalyst for gaseous acetaldehyde degradation. Environ. Sci. Technol. 46, 7741-7745 (2012).

57. Makino, K., Hagiwara, T. \& Murakami, A. A mini review: fundamental aspects of spin trapping with DMPO. Radiat. Phys. Chem. 37, 657-665 (1991).

58. Miyauchi, M. Photocatalysis and photoinduced hydrophilicity of $\mathrm{WO}_{3}$ thin films with underlying Pt nanoparticles. Phys. Chem. Chem. Phys. 10, 6258-6265 (2008)

59. Allard, S., Gunten, U., Sahli, E., Nicolau, R. \& Gallard, H. Oxidation of iodide and iodine on birnessite $\left(\delta-\mathrm{MnO}_{2}\right)$ in the $\mathrm{pH}$ range 4-8. Water Res. 43, 3417-3426 (2009).

60. US EPA. Integrated Risk Information System (IRIS) on Acetaldehyde (National Center for Environmental Assessment, 1999).

61. Janssen, L. J. J. \& Blijlevens, M. H. A. Electrochemical oxidation of iodate to periodate. Electrochim. Acta 48, 3959-3964 (2003).

62. Jiang, X. et al. Hydrophobic organic components of ambient fine particulate matter (PM2.5) associated with inflammatory cellular response. Environ. Sci. Technol. 53, 10479-10486 (2019).

63. Long, C., Liu, P., Li, Y., Li, A. M. \& Zhang, Q. X. Characterization of hydrophobic hypercrosslinked polymer as an adsorbent for removal of chlorinated volatile organic compounds. Environ. Sci. Technol. 45, 4506-4512 (2011).

64. Popat, S. C. \& Deshusses, M. A. Biological removal of siloxanes from landfill and digester gases: opportunities and challenges. Environ. Sci. Technol. 42, 8510-8515 (2008).

65. Mrowetz, M., Balcerski, W., Colussi, A. J. \& Hoffmann, M. R. Oxidative power of nitrogen-doped $\mathrm{TiO}_{2}$ photocatalysts under visible illumination. J. Phys. Chem. B 108, 17269-17273 (2004).

66. Hutter, J., Iannuzzi, M., Schiffmann, F. \& VandeVondele, J. CP2K: atomistic simulations of condensed matter systems. WIREs Comput. Mol. Sci. 4, 15-25 (2014).

67. Perdew, J. P., Burke, K. \& Ernzerhof, M. Generalized gradient approximation made simple. Phys. Rev. Lett. 77, 3865-3868 (1996).

68. Grimme, S. Semiempirical GGA-type density functional constructed with a long-range dispersion correction. J. Comput. Chem. 27, 1787-1799 (2006).
69. VandeVondele, J. \& Hutter, J. Gaussian basis sets for accurate calculations on molecular systems in gas and condensed phases. J. Chem. Phys. 127, 114105 (2007).

70. Goedecker, S., Teter, M. \& Hutter, J. Separable dual-space Gaussian pseudopotentials. Phys. Rev. B 54, 1703-1710 (1996).

\section{Acknowledgements}

This work was supported by the Leading Researcher Program (NRF-2020R1A3B2079953) and Korea Research Fellowship Program (Grant No. 2018H1D3A1A02038503), which were funded by the Korea government (MSIT) through the National Research Foundation of Korea (NRF).

\section{Author contributions}

F.H. conceived and performed the experimental studies, data-analysis, and wrote the manuscript. S.W. and M.W.C. conducted the in situ DRIFT test. W.J. helped with the experimental studies and equipment set-up. W.C. supervised the whole project, revised and reviewed the manuscript.

\section{Competing interests}

The authors declare no competing interests.

\section{Additional information}

Supplementary information The online version contains supplementary material available at https://doi.org/10.1038/s41467-021-26541-z.

Correspondence and requests for materials should be addressed to Wonyong Choi.

Peer review information Nature Communications thanks Mingshan Zhu, Zhigang Zou and the other, anonymous, reviewer for their contribution to the peer review of this work. Peer reviewer reports are available.

Reprints and permission information is available at http://www.nature.com/reprints

Publisher's note Springer Nature remains neutral with regard to jurisdictional claims in published maps and institutional affiliations.

\begin{abstract}
cc) (i) Open Access This article is licensed under a Creative Commons C. Attribution 4.0 International License, which permits use, sharing, adaptation, distribution and reproduction in any medium or format, as long as you give appropriate credit to the original author(s) and the source, provide a link to the Creative Commons license, and indicate if changes were made. The images or other third party material in this article are included in the article's Creative Commons license, unless indicated otherwise in a credit line to the material. If material is not included in the article's Creative Commons license and your intended use is not permitted by statutory regulation or exceeds the permitted use, you will need to obtain permission directly from the copyright holder. To view a copy of this license, visit http://creativecommons.org/ licenses/by/4.0/.
\end{abstract}

(C) The Author(s) 2021 